OPEN ACCESS

Edited by:

Jess Melbourne-Thomas, Oceans and Atmosphere (CSIRO),

Australia

Reviewed by:

Miguel Alfonso Ortega-Huerta,

National Autonomous University

of Mexico, Mexico

Ceridwen I. Fraser,

Australian National University,

Australia

*Correspondence:

Susie M. Grant

suan@bas.ac.uk

Specialty section:

This article was submitted to

Conservation and Restoration

Ecology,

a section of the journal

Frontiers in Ecology and Evolution

Received: 31 October 2020

Accepted: 14 May 2021

Published: 24 June 2021

Citation:

Grant SM, Waller CL, Morley SA, Barnes DKA, Brasier MJ, Double MC, Griffiths $H J$, Hughes KA, Jackson JA, Waluda CM and Constable AJ (2021) Local Drivers of Change in Southern Ocean Ecosystems: Human Activities

and Policy Implications.

Front. Ecol. Evol. 9:624518. doi: $10.3389 /$ fevo.2021.624518

\section{Local Drivers of Change in Southern Ocean Ecosystems: Human Activities and Policy Implications}

\author{
Susie M. Grant ${ }^{1 *}$, Cath L. Waller ${ }^{2}$, Simon A. Morley ${ }^{1}$, David K. A. Barnes ${ }^{1}$, \\ Madeleine J. Brasier', Mike C. Double ${ }^{4}$, Huw J. Griffiths' ${ }^{1}$, Kevin A. Hughes', \\ Jennifer A. Jackson', Claire M. Waluda ${ }^{1}$ and Andrew J. Constable, ${ }^{3,4}$
}

${ }^{1}$ British Antarctic Survey, Cambridge, United Kingdom, ${ }^{2}$ Faculty of Science and Engineering, University of Hull, Hull, United Kingdom, ${ }^{3}$ Institute for Marine and Antarctic Studies, University of Tasmania, Hobart, TAS, Australia, ${ }^{4}$ Department of Agriculture, Water and the Environment, Australian Antarctic Division, Kingston, TAS, Australia

Local drivers are human activities or processes that occur in specific locations, and cause physical or ecological change at the local or regional scale. Here, we consider marine and land-derived pollution, non-indigenous species, tourism and other human visits, exploitation of marine resources, recovery of marine mammals, and coastal change as a result of ice loss, in terms of their historic and current extent, and their interactions with the Southern Ocean environment. We summarise projected increases or decreases in the influence of local drivers, and projected changes to their geographic range, concluding that the influence of non-indigenous species, fishing, and the recovery of marine mammals are predicted to increase in the future across the Southern Ocean. Local drivers can be managed regionally, and we identify existing governance frameworks as part of the Antarctic Treaty System and other instruments which may be employed to mitigate or limit their impacts on Southern Ocean ecosystems.

Keywords: Southern Ocean, climate change, fishing, pollution, non-indigenous species, tourism, Antarctic Treaty System, CCAMLR

\section{INTRODUCTION}

The environment and ecosystems of the Southern Ocean are influenced by phenomena such as atmospheric and oceanic circulation acting at a global scale, as well as by human activities or processes that cause physical or ecological change in specific locations. These influences, or drivers of ecosystem change, may act in distinct ways in different regions, operate at different spatial scales and rates of change, and often interact with each other (Millennium Ecosystem Assessment, 2005). In the context of the Marine Ecosystem Assessment of the Southern Ocean (MEASO), local drivers are defined as those that influence ecosystems at a particular location or series of locations within the Southern Ocean, that can often be managed regionally. In contrast, global drivers have an influence over the whole of the Southern Ocean, and need to be managed through global initiatives (Morley et al., 2020).

The local drivers considered here are: pollution (both marine and land-derived), nonindigenous species (NIS), tourism and other human visits, recovery of previously exploited marine mammals, fishing, and coastal change as a result of ice loss and iceberg scour (Figure 1). This paper focuses on the ten Antarctic and sub-Antarctic MEASO areas which broadly cover (but do not align precisely with) the area managed by the Commission for the Conservation of Antarctic Marine Living Resources (CCAMLR) (Figure 2). These sectors encompass the coastlines 
of the Antarctic continent and its outlying islands and the sub-Antarctic islands, where the majority of scientific research stations and tourist landing sites are located (Figure 3 ). The areas most visited by humans tend to be the best studied, where the trends and impacts are best known.

Even in one of the least impacted oceans on Earth (Halpern et al., 2008), local drivers have at times been greater than can be sustained by the environment, and whilst drivers such as the presence of non-indigenous species and iceberg scour may be projected to increase in particular locations, others, such as the exploitation of marine mammals, and land-derived pollution, have passed their historic peak and have either ceased altogether or are declining (Duarte et al., 2020). The specific effects of local drivers on Southern Ocean species and ecosystems are dealt with in other papers published in this research topic (e.g., Bestley et al., 2020; Brasier et al., 2021; Caccavo et al., in press; Johnston et al., in review; McCormack et al., in review). Cavanagh et al. (2021) also considers the risk of climate change acting together with local human activities, and future impacts on the capacity of the ecosystem to deliver services such as fisheries.

The nature and scale of local drivers have differing consequences and magnitude at locations around continental Antarctica and the sub-Antarctic islands. Here, we assess the status of local drivers in the main regions of human activity of the Southern Ocean. As far as possible, given that records are limited prior to the 1980s, we assess the status and trends of drivers in the past. In doing so, we seek to establish a baseline of information on historical local drivers for use in ecological assessments of how Southern Ocean ecosystems have changed and may be changing in the future.

Monitoring the magnitude of some local drivers (such as fishing effort), and their impacts in specific locations (e.g., point source pollution at some research stations) provides a medium to high level of certainty on recent trends. However, the absence of monitoring of local drivers and related biological and environmental parameters across much of the Southern Ocean means that levels of certainty about the nature and extent of impacts and projected trends are generally low for those remote areas. No single driver acts in isolation and there is a high level of certainty that cumulative impacts will result from the interaction of local drivers with global drivers, despite a lack of understanding of the specific effects and projections of such interactions.

All human activities in the Southern Ocean, other than whaling, are regulated under the instruments of the Antarctic Treaty System (ATS). While this management aims to minimise impacts to the environment (Hughes et al., 2018), and to assess the cumulative impacts and interactions of both local and global drivers and their projected trends, this has not yet been fully achieved in practice. This is due in part to the separate consideration of different human activities by different components of the ATS (Grant et al., 2013), as well as a lack of integrated consideration of the effects of global drivers such as temperature, ocean circulation or sea ice extent within management frameworks (CCAMLR, 2017).

Since the first humans arrived in the region during the late 18 th century and began to exploit its living resources, local drivers have had an impact on Southern Ocean ecosystems. The initially uncontrolled harvesting of marine mammals (firstly of fur seals, followed later by elephant seals and whales), as well as penguins hunted for oil, resulted in sharp declines of local and regional populations, and the assumed local extinction of some species, such as Antarctic fur seals at South Georgia (Hoffman et al., 2011). Harvesting of finfish was first undertaken in the Southern Ocean in the 1960s, contributing to the collapse of fish stocks that have yet to recover (e.g., notothenioids in the Scotia Sea region, Kock et al., 2007). This was followed by the start of krill fishing in the 1970s, and fishing remained unregulated until the establishment of CCAMLR in 1982, but even then controls on fisheries took some years to develop (Constable et al., 2000). The near extirpation of many large cetaceans over a sustained period during the peak of whaling activities during the first half of the 20th century may have further consequences as these species continue to recover (Roman et al., 2014). Whilst CCAMLR's current management measures aim to uphold the precautionary approach of ensuring that activities should have a low risk of causing long-term adverse effects, fishing activities still have the potential to drive change in populations of harvested species, as well as those of associated and dependent species, such as the decline of albatross populations as a result of incidental mortality in the toothfish fishery (Michael et al., 2017; Pardo et al., 2017; Bestley et al., 2020). Local drivers, including the activities of single fishing vessels, can therefore contribute to regional, long-term change.

With no Indigenous population on the Antarctic continent, or on most sub-Antarctic islands (with the exception of Polynesians thought to have visited and occupied some of the New Zealand sub-Antarctic islands as early as the 12th century), human activities on land have only had an impact since the first visits of sealers and explorers in the early 19th century. It was not until the second half of the 20th century that the footprint of land-based human activity began to expand, with scientific research and subsequently tourism both increasing in recent decades, in terms of numbers and geographical scope, as well as a diversification of activities (Pertierra et al., 2017; Brooks S.T. et al., 2019). The numbers of people visiting the Antarctic continent and subAntarctic islands remain very low, with the vast majority of the coastline and the interior rarely or never visited. Nevertheless, localised human activities on land have the potential to change or disrupt marine species and ecosystems at a local or even regional scale, especially where multiple drivers interact to generate cumulative impacts, where they are exacerbated by the effects of global drivers such as warming temperatures, or where they are the result of accidents or unforeseen events.

Here, we discuss specific local drivers in terms of their known current spatial and temporal extent, and their interactions with the Southern Ocean environment. We also reflect on how these local drivers may be positively or negatively affected by others, including global drivers. We summarise projected increases or decreases in the influence of local drivers, and projected changes to their geographic range, based on evidence from the scientific literature. Where appropriate, the level of confidence in a conclusion is given according to the approach of the IPCC (Mastrandrea et al., 2011). When not supported by a reference 


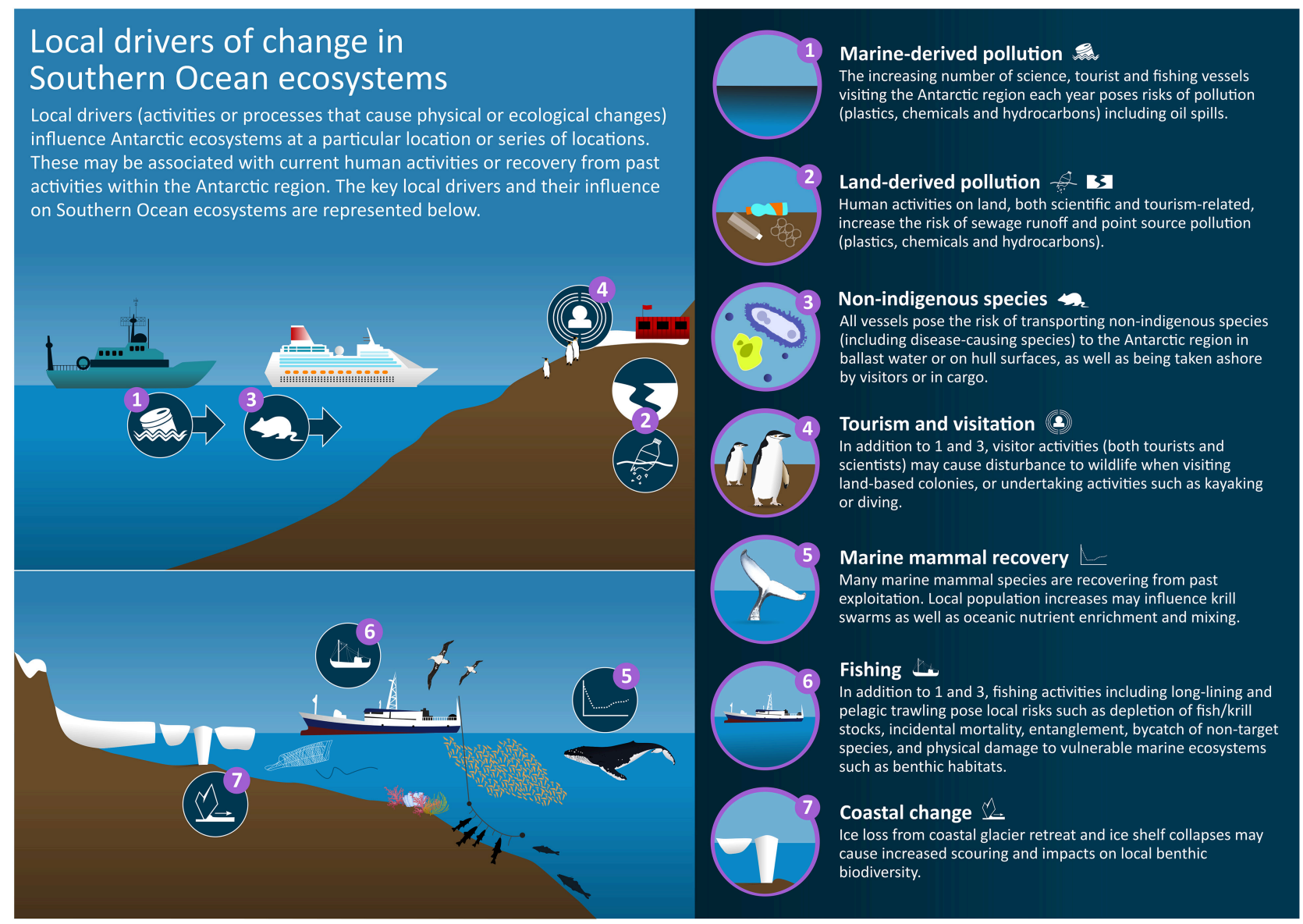

FIGURE 1 | Summary of local drivers of change influencing Southern Ocean ecosystems.

cited in the text, we judged confidence from the levels of agreement we observe in the scientific literature and the amount of evidence presented to support the conclusion, including consideration of any contrary evidence. The levels of confidence are not to be used as the inverse of confidence for alternative hypotheses, as those alternatives may not be addressed in the literature. Finally, we identify existing governance frameworks as part of the ATS and other instruments that have specific relevance to local drivers, and which may be employed to mitigate or limit their impacts on Southern Ocean ecosystems (Lee and Chown, 2007).

\section{LOCAL DRIVERS}

\section{Marine-Derived Pollution}

The Southern Ocean has relatively few direct sources of humanderived marine waste, so the input of pollutants is primarily from local shipping, fisheries, research station resupply activities or transported from further afield (Slip and Burton, 1991; Walker et al., 1997; Barnes et al., 2010; Waller et al., 2017; Ryan et al., 2019). Despite its remote location and distance from human habitation, the impact of marine debris on
Southern Ocean wildlife has been reported since the 1970s. This includes entanglement of marine mammals (Payne, 1979; Bonner and McCann, 1982; Arnould and Croxall, 1995; Waluda and Staniland, 2013), and the ingestion and entanglement of debris by seabirds (Van Franeker and Bell, 1988; Huin and Croxall, 1996; Nel and Nel, 1999; Ryan et al., 2016; Phillips and Waluda, 2020). Beached marine debris has been reported from various oceanic shores in the Southern Ocean (Gregory et al., 1984; Ryan, 1987; Slip and Burton, 1991; Torres and Jorquera, 1995; Gregory and Ryan, 1997; Walker et al., 1997; Convey et al., 2002; Barnes and Fraser, 2003; Monteiro et al., 2018; Waluda et al., 2020). Floating debris such as fishing buoys and packaging bands have also been observed as far south as $73^{\circ} \mathrm{S}$, in the Bellingshausen Sea (Barnes et al., 2010). In addition to this "macro-debris" (i.e., items $>5 \mathrm{~mm}$ ), recent work has suggested that microplastics (items $<5 \mathrm{~mm}$; Thompson et al., 2004), from both primary sources and the breakdown of larger items, are an emerging area of concern in the Southern Ocean. To date, microplastics have been found in pelagic waters (Isobe et al., 2017; Lacerda et al., 2019; Suaria et al., 2020), shallow marine sediments (Waller et al., 2017; Reed et al., 2018), benthic invertebrates (Sfriso et al., 2020), pelagic invertebrates (Jones-Williams et al., 2020), seals (Eriksson and Burton, 2003), 


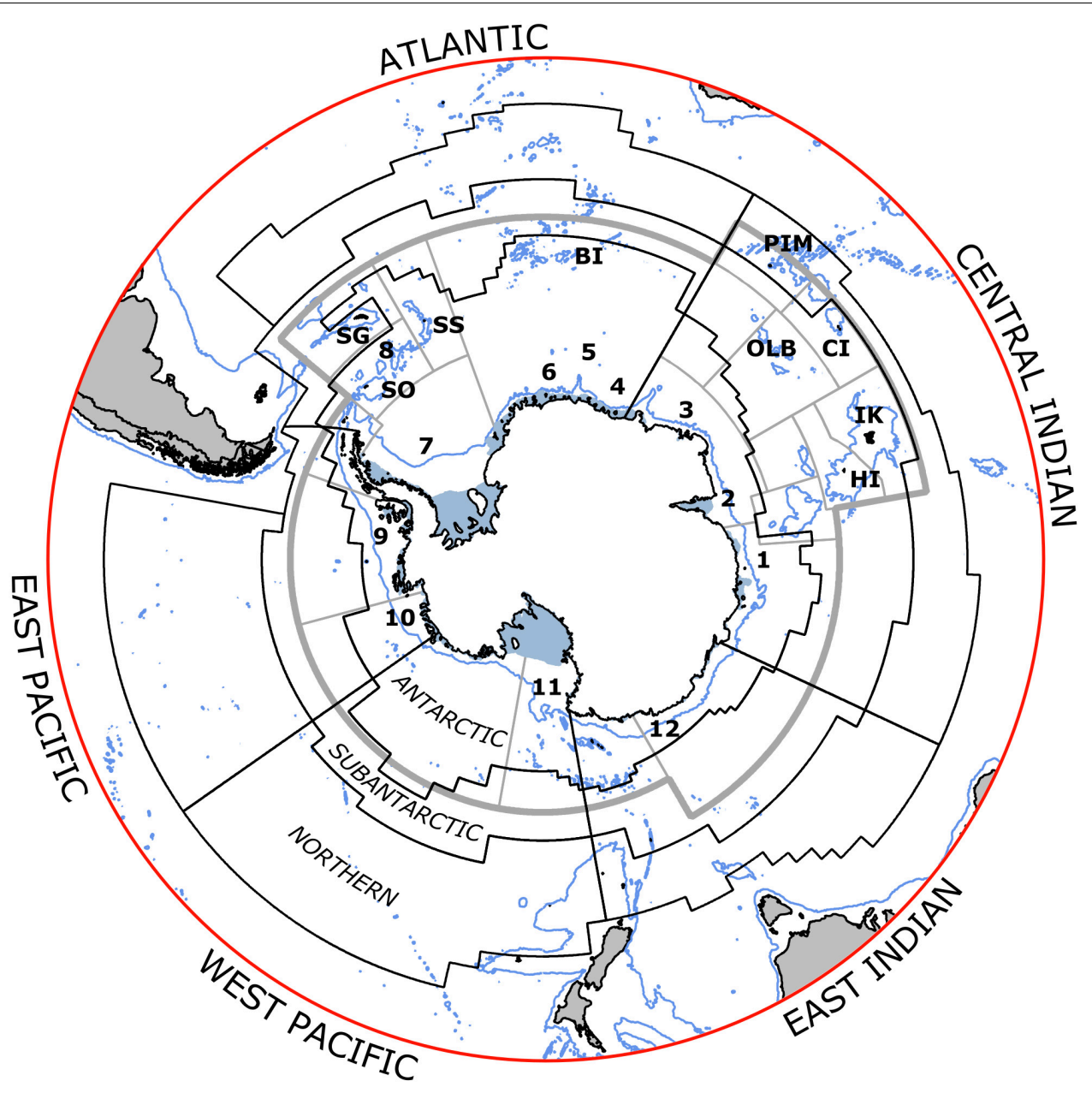

FIGURE 2 | Areas for assessing status and trends of local drivers in the Marine Ecosystem Assessment for the Southern Ocean (black lines). Sectors are divided meridionally: corresponding names of sectors are outside the circle. Zones extend from the coast to the Southern Antarctic Circumpolar Front (Antarctic), to the Subantarctic Front (Subantarctic) and to the Subtropical Front (Northern). Seas are marked in the Antarctic Zone as (1) Davis, (2) Cooperation, (3) Cosmonaut, (4) Riiser-Larsen, (5) Haakon VII, (6) Lazarev, (7) Weddell, (8) Scotia, (9) Bellingshausen, (10) Amundsen, (11) Ross, (12) Dumont D'Urville. Islands in the CCAMLR area include Heard (HI), Isle Kerguelen (IK), Crozet (CI), Prince Edward-Marion (PEM), Bouvet (BI), South Sandwich (SS), South Georgia (SG), South Orkney (SO), Ob and Lena Banks (OLB), and South Shetlands (not initialled but found on the north-western side of Antarctic Peninsula). Grey lines indicate the CCAMLR reporting areas (Subareas and Divisions).

and penguins (Bessa et al., 2019; Le Guen et al., 2020). While current concentrations of microplastics may be negligible on the Southern Ocean scale, they can be high at local scales if concentrated at point sources (Waller et al., 2017). The seafloor is often a final resting place for marine debris and microplastics, even in the Southern Ocean (Cunningham et al., 2020), although the impact on benthic species or foodwebs remains largely unknown (Horton and Barnes, 2020; Brasier et al., 2021).

The risk from point sources of pollution is highest on the northwest Antarctic Peninsula as this area has the highest human footfall including 35 coastal research stations (46\% of the total number of research stations across the Antarctic continent) (COMNAP, 2017), and all of the top twenty most visited Antarctic tourist sites, which accounted for $68 \%$ of all landings in the 2017/18 season (IAATO, 2018) (see Figure 3).
Although they occur rarely, oil spills can have a greater significance in Antarctica then elsewhere in the world (Clarke and Harris, 2003), with substantial impacts on sediment meiofauna (Stark et al., 2017), littoral species (Kennicutt, 1990) and seabirds (Reid, 1995). The largest reported spills have been due to the sinking of vessels, including the ARA Bahia Paraiso (1989, $600,000 \mathrm{~L}$ diesel released near the US Palmer Station, Antarctic Peninsula), MV Nella Dan (1987, 270,000 L light marine diesel released near Macquarie Island, sub-Antarctic) and MV Explorer (2007, 185,000 L diesel released near King George Island, South Shetland Islands), which resulted in impacts including the mortality of marine and intertidal invertebrates, oiling of penguins, and reproductive failures and declines observed in local bird populations (Eppley and Rubega, 1990; Kennicutt, 1990; Kennicutt et al., 1991; Smith and Simpson, 1995; Chile, 2008). 


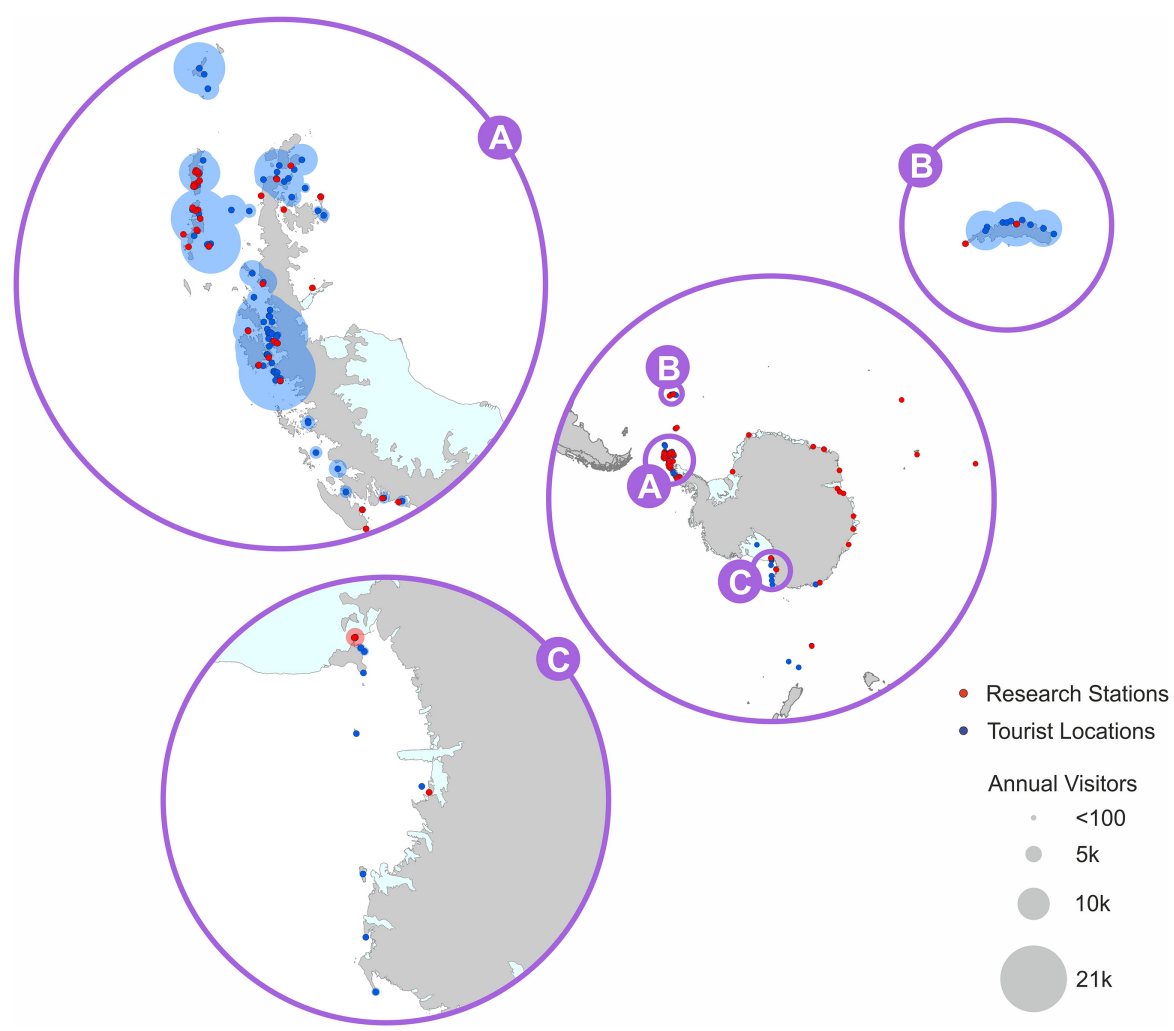

FIGURE 3 | Regions of highest land-based human activity (scientific research stations and tourist visits). Maximum occupancy of coastal Antarctic research stations (www.comnap.aq) and mean annual visitor numbers (2003/4-2014/15 seasons - IAATO) for Antarctica and the 2014/2015 season for South Georgia (www.gov.gs).

Most microplastics and other pollutants are global in origin and transported into the Southern Ocean through atmospheric and oceanic teleconnections. The transport of plastics, heavy metals and other pollutants in the Southern Ocean via the atmosphere, cryosphere and ocean currents is further considered in Morley et al. (2020). The impacts of persistent organic pollutants (POPs) originating from outside the Southern Ocean on higher predators are also discussed in Bestley et al. (2020).

\section{Land-Derived Pollution}

Across Antarctica, research stations and land-based scientific activities can act as local sources of land-derived pollution, hydrocarbons, POPs, wastewater effluent, and macro- and microplastics (Munari et al., 2017; Reed et al., 2018; Absher et al., 2019), with impacts observed predominantly at a local scale (Tin et al., 2009). Operation of ships, aircraft, research stations and field camps in Antarctica relies upon the combustion of hydrocarbons as a fuel source. Currently $58 \%$ of coastal research stations use a combination of fossil fuels and renewable energy. Logistical support for these stations also represents a potential pollutant load with $\sim 555$ ship visits and 547 flights annually (data from COMNAP, 2017). Potential negative environmental consequences of spills are made all the more serious due to the typical lack of capacity within national Antarctic programmes to mount effective clean-up operations in the event of an incident.
Under the Protocol on Environmental Protection to the Antarctic Treaty (agreed 1991, entered into force 1998 ${ }^{1}$ ), the disposal of most wastes within the Antarctic Treaty area (the area south of latitude $60^{\circ} \mathrm{S}$ ) is prohibited. This includes the discharge of oil, noxious liquid substances and garbage from ships, but disposal of food waste and sewage is permitted within 12 nautical miles of the coast. National Antarctic programmes are encouraged to remove sewage and domestic liquid waste generated at research stations; however, due to the logistical difficulties of removing sewage waste from Antarctica, coastal research stations may dispose of sewage into the near-shore environment, provided there is capacity for initial dilution and rapid dispersal. No treatment of the sewage waste is required under the Protocol, except for maceration in cases where the number of personnel on station exceeds c. 30 individuals. Sewage can contain non-native microorganisms, pathogens, genetic fragments and a wide range of pollutants including heavy metals, hydrocarbons, detergents, microplastics and flameretardant chemicals (for reviews see: Tin et al., 2009; Waller et al., 2017; Stark et al., 2019). Viable sewage-associated bacteria have been detected in high concentrations around outfalls and up to $2 \mathrm{~km}$ away, along with above-background concentrations of heavy metals, persistent organic pollutants (Hale et al., 2008; Wild et al., 2015; Stark et al., 2016), and other organic contaminants

\footnotetext{
${ }^{1}$ https://www.ats.aq/e/protocol.html
} 
(Emnet et al., 2015), hydrocarbons, nutrients and faecal sterols in marine sediments (Lenihan and Oliver, 1995; Hughes, 2004; Hughes and Nobbs, 2004; Hughes and Thompson, 2004; Leeming et al., 2015; Stark et al., 2016).

The impacts of long-term sewage release to near-shore environments is not well understood, but sewage release from research stations has caused local changes in benthic biodiversity and abundance and may have implications for wildlife health (Conlan et al., 2004; Stark et al., 2016). In light of developments in sewage treatment technologies, the minimum standards set out in the Protocol may no longer be considered acceptable by some Parties, and increasing numbers of sewage treatment plants are being installed, particularly at larger Antarctic research stations (Hughes, 2003; Gröndahl et al., 2008; Brasier et al., 2021).

Other sources of Antarctic marine pollution from research stations may include macroplastics that are blown into the ocean, due to poor waste management, or historical waste that was discarded prior to the entry into force of the Protocol (Crockett and White, 2003). Historic waste dumps located on ice sheets or ice shelves may also emerge at the ice front to be released into the marine environment, for example, the buried and abandoned Halley III Research Station calved off the Brunt Ice Shelf into the Weddell Sea in 1993 (Aronson et al., 2011). Following deployment, scientific instrumentation may also be inadvertently or knowingly lost to the marine environment. Examples include meteorological radiosondes and balloons, expendable bathythermographs (XBTs), seabed experimental apparatus damaged by iceberg collisions, lost Argo floats or autonomous underwater vehicles and unrecoverable weights to which scientific devices are attached.

With a more comprehensive understanding and implementation of the Protocol, including improving waste management practices, levels of environmental pollution may decline, particularly as alternative technologies for power generation are employed (e.g., the Belgian Princess Elisabeth Station $^{2}$ ). Nevertheless, as more research stations continue to be established in previously little impacted locations (e.g., the Turkish station on Horseshoe Island, Antarctica Peninsula, and new Chinese Station on Inexpressible Island, Ross Sea Region) and the human footprint across the continent expands, minimising environmental impacts becomes ever more important if SO marine environments are to remain close to pristine (Brooks S.T. et al., 2019). Locations with concentrations of research station infrastructure may be particularly vulnerable to marine pollution, particularly where aging infrastructure has led to chronic or catastrophic fuel spills that have affected the marine environment (Wilkness, 1990; Peter et al., 2008).

\section{Tourism and Visitation}

Antarctic tourism began in the 1950s and today is one of the three most significant human activities undertaken in the region, alongside scientific research and commercial fishing. In general, the impacts caused by national governmental operators in their delivery of science and other strategic priorities through the construction of research stations and other infrastructure may

${ }^{2}$ http://www.antarcticstation.org/station/renewable_energies be locally greater than the impacts caused by Antarctic tourism (Tin et al., 2009). However, the growth of the tourism industry, and increasing diversity of activities it provides, will contribute to increasing human footprint in Antarctica, with a resulting loss of wilderness and increase in local human impact (Eijgelaar et al., 2010; Liggett et al., 2011; Pertierra et al., 2017). Since its establishment in 1991 the majority of Antarctic tour operators are members of the industry body IAATO (International Association of Antarctica Tour Operators), which coordinates tourism shipping activities and represents the industry at the normally annual Antarctic Treaty Consultative Meeting.

While the Antarctic tourist industry is driven by global demand, tourist activities influence sites at a local scale. The majority $(>95 \%)$ of tourism activity occurs in the Antarctic Peninsula region, but visitors also travel in smaller numbers to the Ross Sea, and sites along the coast of East Antarctica (Figure 3). Most tourists visit Antarctica on cruise vessels that call at a number of coastal sites for brief shore-based activities, after which they return to the vessel. Around 50 yachts travel to the Antarctic each year, which can be commercial operations as well as private exploration (United Kingdom, Argentina, Chile in conjunction with the International Association of Antarctica Tour Operators, 2018). In recent years the tourist season has been extended to more than 150 days (November to April) due to the use of icestrengthened passenger vessels, with an associated steep rise in tourist numbers. The 2018-2019 season recorded an increase of $8 \%$ from the previous year, with a total of 56,186 tourists visiting. Numbers increased again by $32 \%$ to 74,401 for the $2019 / 2020$ season (IAATO, 2019), although this was curtailed in early 2020 due to the effects of COVID-19. The 2020/2021 season saw a near cessation of Antarctic tourism due to the pandemic, and it is not known how long it will take for the cruise industry to recover (Hughes and Convey, 2020).

Tourism has occurred at c. 250 locations in Antarctica, with the great majority concentrated at a small number of sites located on the northern Antarctic Peninsula and offshore islands (e.g., Neko Harbour, Goudier Island, Half Moon Island and Cuverville Island). Bender et al. (2016) reported that in the 2013/2014 season, just 15 of the Antarctic Peninsula sites made up $68 \%$ of all passenger landings. The level of human impact at these sites will depend upon their resilience, however, few sites have been assessed and monitored in this regard (see Tejedo et al., 2012, 2020; Russell et al., 2013).

Impacts caused by increasing visitation and the potential establishment of permanent infrastructure (noting that these are not exclusive to tourism) could include: a loss of wilderness and aesthetic values (Summerson and Tin, 2018), increased risk of the introduction of non-indigenous species (Chown et al., 2012), increased risk of pollution events at both small (e.g., dropping of litter) and large scale [e.g., fuel spill from a ship (Aronson et al., 2011)], disturbance of wildlife by humans (Burger and Gochfeld, 2007; Tejedo et al., 2016; Dunn et al., 2019) or aircraft (Hughes et al., 2008), increased atmospheric emissions from vessels, aircrafts and land vehicles (Amelung and Lamers, 2007; Eijgelaar et al., 2010) and increasing cumulative impacts at ice-free locations where scientific, logistic and tourism activities coincide (e.g., Deception Island) (Pertierra et al., 2014). 
Predicted climate change impacts such as increases in the area of ice-free ground (Lee et al., 2017), reductions in sea ice extent, and shifts in the distribution ranges of wildlife, are likely to affect the tourism industry by potentially changing access to established visitor sites, facilitating access to new locations and affecting the wildlife present at established landing sites.

An increasingly diverse range of activities are available to tourists including overnight camping, mountain climbing, visits to penguin colonies (including emperor penguins), whale watching, trips on small boats, swimming, SCUBA and submersible diving, underwater Remotely Operated Vehicles (ROVs), Remotely Piloted Autonomous Systems (RPAS), standup paddle boarding, photography, helicopter flights, kayaking, skiing/snowboarding, research station visits, as well as more extreme activities such as marathon running, long distance treks (e.g., by ski or using kites), paragliding, heli-skiing and base jumping. Many of these activities may have direct impacts upon marine species, either through disturbance of a range of biological groups [e.g., from the disturbance of benthic sediment population by the now prohibited practice of digging geothermally-heated bathing pits at the shoreline on Deception Island, to disturbance resulting from visitation of penguin colonies (Dunn et al., 2019)], generation of underwater noise (ROVs, large and small boat operations) and potential dispersal of non-native species [i.e., through repeated use of equipment at a series of locations without adequate cleaning during intervening periods (McCarthy et al., 2019)]. As ship traffic has continued to increase, the risk of ship strikes of whales has also increased, with nine whale strikes reported by IAATO to the International Whaling Commission (IWC) since 2001. Recognising this, IAATO has introduced new procedures for operations in the vicinity of whales, including limiting vessel speed to 10 knots at two marine sites to the west of the Antarctic Peninsula (IAATO, 2019).

\section{Non-indigenous Species (NIS)}

Antarctica and the outlying islands within the Polar Front typically have the highest proportion of native species of any global localities. For example of the $>1,200$ species recorded from the South Orkney archipelago, only two (0.2\%) are considered to be non-indigenous (Barnes et al., 2009) and some southern polar islands such as McDonald and Bouvetoya may even have none (Frenot et al., 2005). It is now clear that the Polar Front has more porosity than once thought (Barnes et al., 2006), yet still presents a considerable obstacle isolating the Southern Ocean from much species transport from elsewhere (Clarke et al., 2005). However, ships, aircraft and even plastic now cross the Southern Ocean, potentially carrying non-indigenous species (Lewis et al., 2003; Morley et al., 2020), although the risk is geographically uneven given the distribution of stations and tourist sites (Figure 3), and more risk is borne by the more visited Scotia Arc and northern Antarctic Peninsula. Only a small proportion of species which travel such a journey, survive and remain viable, and an even smaller proportion are able to recruit and establish. Environmental conditions are most similar to cool temperate continental shelves around the western Antarctic Peninsula and Scotia Arc, which may increase the risk in these areas. Furthermore, regional warming and sea ice losses have been highest within those areas, and this risk distribution is borne out by establishments of non-indigenous species recorded to date (Frenot et al., 2005; Barnes et al., 2006; Avila et al., 2020; Cárdenas et al., 2020; Hughes et al., 2020). With more research stations, of which several maintain year-round SCUBA activities, this region is also better monitored than elsewhere, although still far from adequate.

Over the last few decades there have been reports of single life stages of several marine species reported from various locations around the Scotia Sea and northern Antarctic Peninsula (for a recent overview see McCarthy et al., 2019). Considerable scientific and public discussion has occurred over the potential changing distributions of native fauna (most obviously stone crabs - Lithodidae) and the possible vulnerability of life on Antarctica's sea beds (Thatje and Fuentes, 2003; Griffiths et al., 2013). A single Mytilid mussel was found at Grytviken, South Georgia (Ralph et al., 1976), and Mytilids have also been reported from King George Island (Cárdenas et al., 2020), but establishment was not recorded in either case. However, new records of macro algae within the caldera at Deception Island may represent new discoveries of indigenous or non-indigenous species, detected due to increased sampling effort (Clayton et al., 1997). An invasive and potentially ecologically harmful bryozoan (Membranipora membranacea) has also been discovered on non-native kelp rafts at Deception Island (Avila et al., 2020). These kelp rafts, usually Durvillaea antarctica or Macrocystis pyrifera, have been demonstrated to be able to cross the Polar Front with evidence from genomics and oceanographic models (Fraser et al., 2018). Recently the polychaete worm Chaetopterus variopedatus has established and started spreading in the shallows at South Georgia (see Hughes et al., 2020). Once established, marine invasions have proved virtually impossible to reverse. There has been considerable concern that non-indigenous species establishments around Antarctica might prove to be particularly devastating because of the long Southern Ocean semi-isolation from biota elsewhere, but also due to the intensity of climate change there (Brasier et al., 2021).

\section{Exploitation of Marine Species}

The long history of human exploitation of marine species in the Southern Ocean developed in a progressive sequence of seals and penguins, whales, finfish, then krill. In terms of methods of exploitation, it went from capturing and killing individual marine mammals, to the use of industrial demersal and pelagic trawls and more recently to the use of demersal longlines to capture toothfish. Illegal, unreported and unregulated (IUU) fishing began in the mid-1990s using longlines but evolved to use indiscriminate gill netting from 2008. Detailed reporting of species caught, along with the geolocation of catches, only began in the 1990s. Most biomass was extracted from the Southern Ocean prior to this time. Here we present the time series of exploitation as best we can from available records to date. These time series indicate the pressures that local exploitation may have had on the species involved, but also the relative difference in food web effects in different MEASO areas. We also report on 


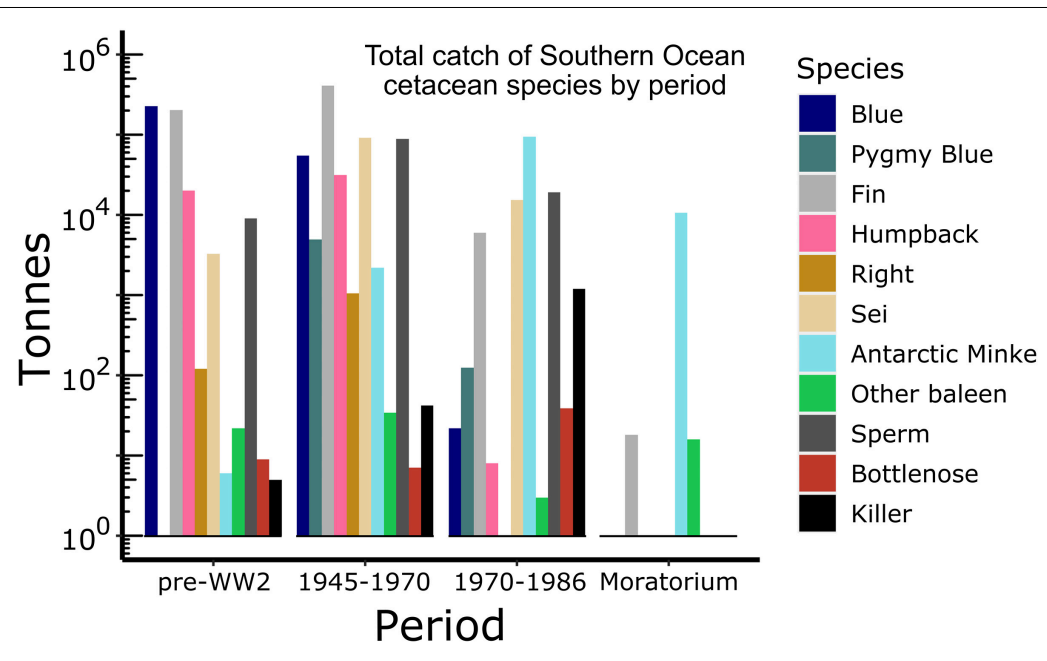

FIGURE 4 | Total catch (tonnes) of Southern Ocean cetacean species (right legend) in four different periods of whaling. Data from IWC Catch Records. Y-axis is on a $\log _{10}$ scale.

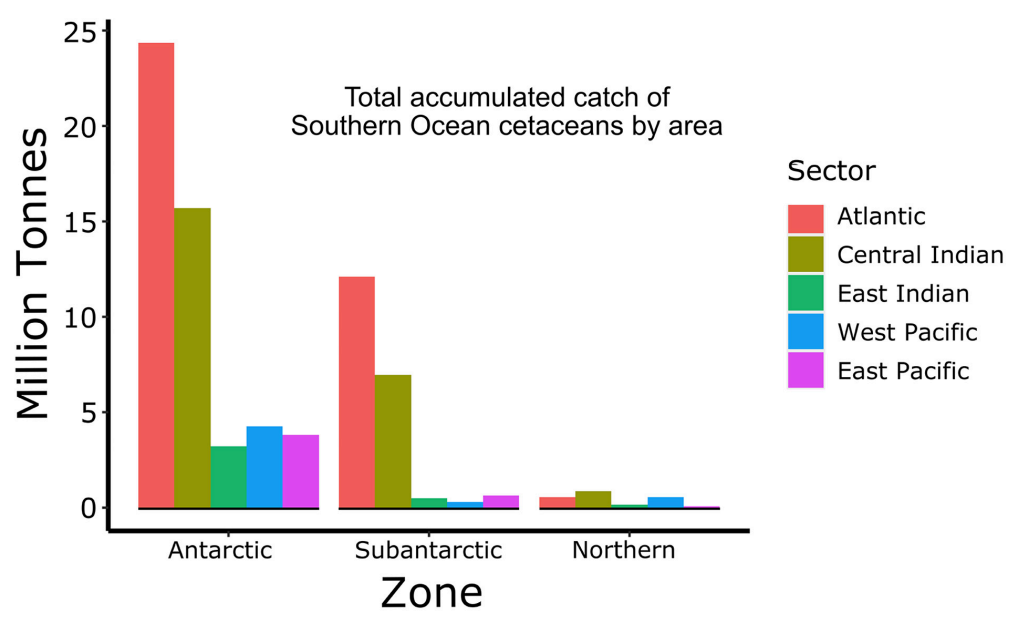

FIGURE 5 | Total accumulated catch (million tonnes) of Southern Ocean cetaceans in each sector (right legend) from each zone of MEASO areas as shown in Figure 2. Data from IWC Catch Records.

'incidental mortality' which is the unintentional capture or death of species not targeted by the fishery.

\section{Marine Mammals}

Exploitation of seals began in the eighteenth century with harvesting mostly occurring in the early 19th century when seal populations were decimated across many of the subantarctic islands. Reconstruction of the catch of seals has been difficult, requiring the interpretation of log books from vessels exploiting seals on subantarctic islands and from trade figures (Foley and Lynch, 2020). For many areas such as in the Indian Ocean sector, few records exist but the reported timeline is similar with the greater part of sealing finishing by the mid-19th century (King, 1959). A reconstruction of the Antarctic fur seal population at South Georgia has estimated annual takes of Antarctic fur seals of up to 150,000 animals on that island alone (Foley and Lynch,
2020). Similar takes are reported for seals and sea lions south of Australia and New Zealand (Ling, 1999).

Pelagic whaling caused the near extirpation of large whale species prior to the moratorium on commercial whaling in 1986 (Rocha et al., 2014). Reconstruction of whale catches has come from log books and records from shore stations and factory vessels during this time. Records are available from the Secretariat of the IWC. The available data on the numbers of different species caught were aggregated into four main periods of whaling - prior to the Second World War (WW2), a period of active whaling from 1945 to 1970, a period where depletions of the larger whales were obvious in the catch records from 1970 to 1986, and the period since the moratorium came into effect (Figure 4).

The potential impacts on the ecosystem of such removals in the different MEASO areas is shown by multiplying the catch in numbers by an approximate average mass of an adult male 

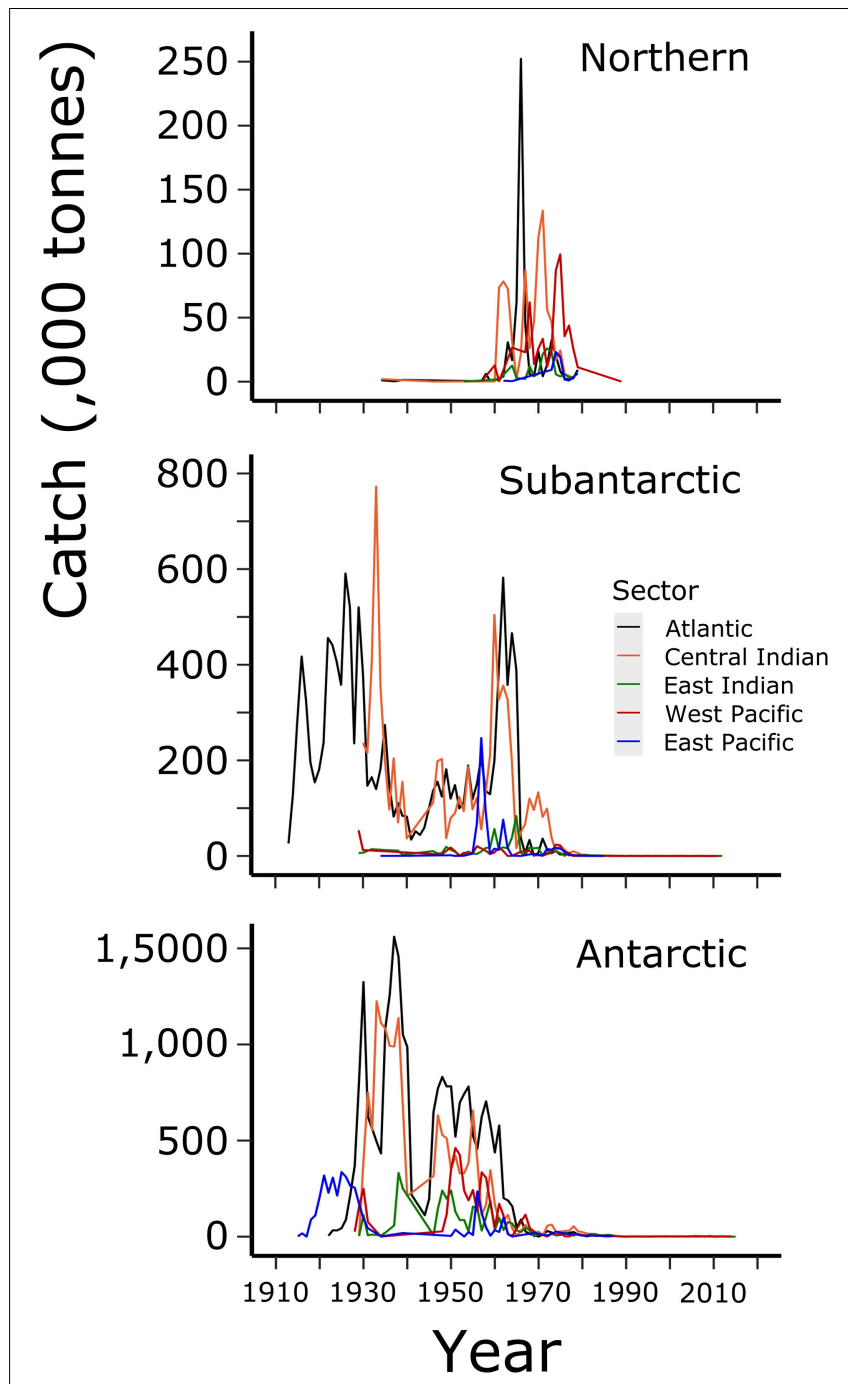

FIGURE 6 | Time series of catches (tonnes) of all Southern Ocean cetaceans in each sector (central right legend) from each zone (labelled panels) of MEASO areas as shown in Figure 2. Data from IWC Catch Records.

whale of each species. We note that these species migrate to lower latitudes of the Southern Hemisphere in winter and many were also hunted there, so these estimates represent a minimum value in terms of biomass removed. Even though this is approximate, the results presented in Figure 5 show that most biomass was removed from the Antarctic Zone followed by the Subantarctic Zone and most direct removals of whales occurred in the Atlantic and Central Indian Sectors.

The time series of biomass removals is shown in Figure 6. The earliest whaling in the 20th century resulted in similar removals from the subantarctic zone in the Atlantic Sector, around South Georgia, and around the Antarctic Peninsula in the East Pacific Sector, as land stations were established in these locations for processing. After that and prior to WW2, the use of factory ships enabled more offshore hunting, with onboard processing eliminating the need to use land stations. Substantial biomass was removed from Antarctic Zone in the Atlantic Sector (Weddell Sea) and from the East Antarctic area of the Central Indian Sector. After WW2, catches were more widespread, including the Ross Sea in the West Pacific Sector in the 1950s and 1960s. By 1970, Southern Ocean areas were considered fished out, and the main fishery had moved north. Hence biomass taken from the Antarctic Zone was negligible compared to steady catches of mostly sei and fin whales in the Subantarctic and Northern Zones of the Central Indian and West Pacific Sectors.

\section{Finfish and Krill}

The dominant fisheries in the Southern Ocean began with groundfish fishing by predominantly the Soviet Union over the 1970s and 1980s (Figures 7, 8). During this time, Notothenia rossii was fished close to extinction throughout the island shelf areas in the Antarctic and Subantarctic Zones of the Southern Ocean (Kock, 1992). Other groundfish species also became depleted throughout the Subantarctic Zone prior to the coming into force of CCAMLR in 1982 (Kock et al., 2007) and ended by 1990 . Two bentho-pelagic species from this period remain targeted in the Southern Ocean. The mackerel icefish, Champsocephalus gunnari, is targeted in the Subantarctic Zone at South Georgia (Atlantic Sector) and Heard Island (Central Indian Sector) using trawls. Toothfish, Dissostichus species, are targeted throughout the Southern Ocean using longlines, although the catch for Dissostichus eleginoides (Patagonian toothfish) in the Subantarctic Zone far outweighs the catch of Dissostichus mawsoni (Antarctic toothfish) in the Antarctic Zone. Fishing for Antarctic krill (Euphausia superba) began in the 1970 s and increased substantially in the 1980s, only to decline again in the 1990s following the collapse of the Soviet Union. Catches of krill are increasing again but are not yet at the levels of the 1980s. Other fisheries that have been explored include squid, mesopelagic fish (mainly myctophids), Antarctic silverfish (Pleuragramma antarctica) and lithodid crabs.

The spatial distributions and time series of catches of target species within each MEASO area were assessed using catch records from the CCAMLR Statistical Bulletin (hereafter referred to as the Bulletin, CCAMLR, 2019) (see outcomes in Figures 9, 10). Rules for distributing catch from CCAMLR's large-scale reporting areas (Subareas and Divisions) into MEASO areas were developed based on the reports of the Scientific Committee and fishery reports published on the CCAMLR website $^{3}$ as well as Kock (1992). Each record in the Bulletin has the reporting area, flag state, year, target species and, in most cases, fishing method. Geographic locations and depth ranges were available in the descriptions of different methods and locations where target species were caught. For CCAMLR reporting areas that overlapped with MEASO areas, catches were partitioned by the proportions of seabed area in the different MEASO areas relative to these locations.

Fisheries for Patagonian toothfish are well established, with integrated assessments using estimated parameters for their stock dynamics along with estimates of abundance are available for the fishery at South Georgia in the Atlantic Sector and Heard

${ }^{3}$ www.ccamlr.org 


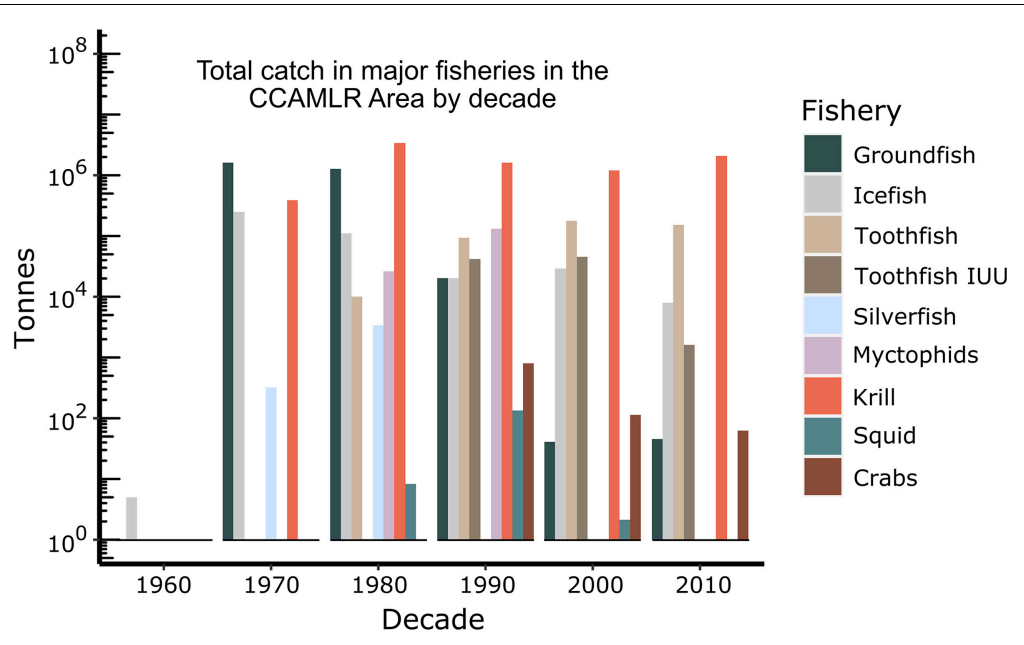

FIGURE 7 | Total catch (tonnes, all taxa) in each major fishery (legend) in the CCAMLR Area in each decade from the 1960 s to the present. Data from the CCAMLR Statistical Bulletin 2019.

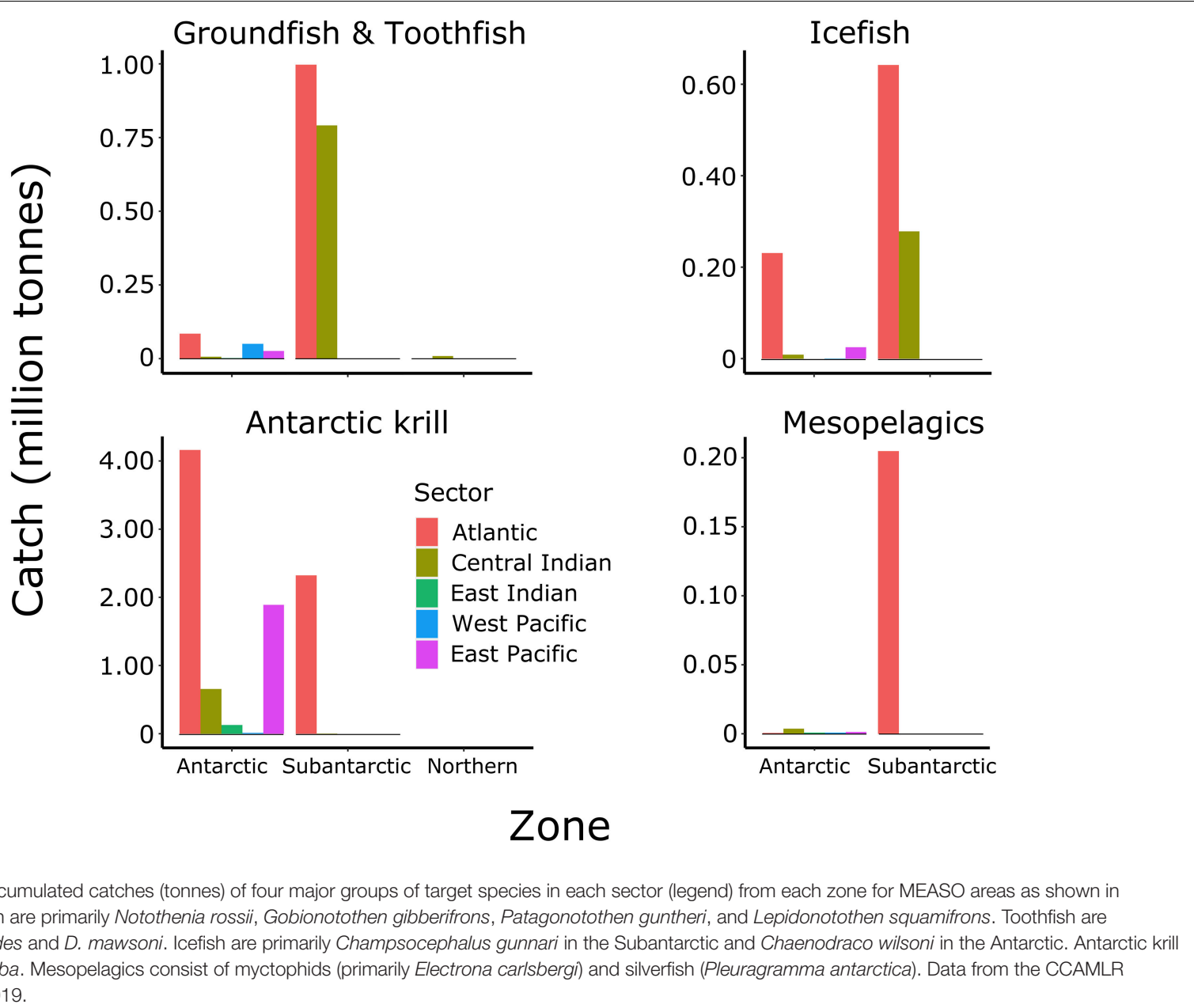

Island in the Central Indian Sector on the Kerguelen Plateau. These fisheries have regular stock assessments and biannual setting of catch limits, based on the use of the CCAMLR decision rule (Constable et al., 2000; Hillary et al., 2006; Candy and Constable, 2008). Also on the Kerguelen Plateau is the largest toothfish fishery around Isles Kerguelen. The Antarctic 

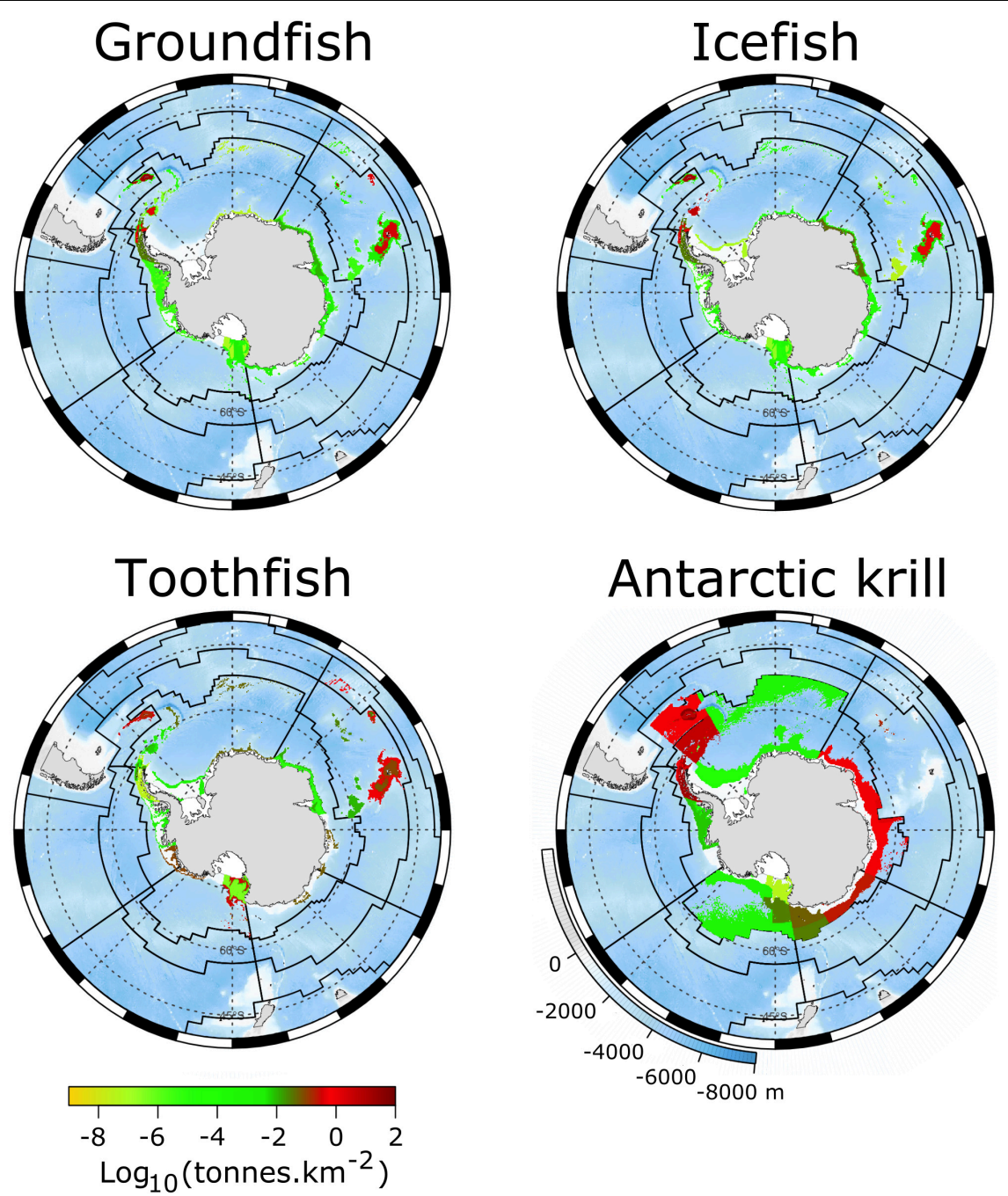

FIGURE 9 | Accumulated catch for groundfish, icefish, toothfish and Antarctic krill from 1970 to 2018 plotted against ocean depth (legend at bottom left of Antarctic krill panel) as catch density (tonnes per square kilometre) on a $\log _{10}$ scale (bottom left legend). Species are those listed in Figure 8. Source data: CCAMLR Statistical Bulletin 2019. Grey lines show a graticule, and black lines show the boundaries of the 15 MEASO areas in Figure 2.

toothfish fisheries around continental Antarctica are classified as exploratory fisheries with the need to have active research programmes to support the development of the fishery. The most advanced of these is the fishery in the Ross Sea, which began in 1998 and also has an integrated assessment (Mormede et al., 2014). The other Antarctic toothfish fisheries remain in early research phases, despite being present for over a decade. Combined, these fisheries are considered to be sustainable (Croxall and Nicol, 2004; Constable, 2011), although the effects of climate change will need to be considered in their management (Nicol et al., 2007; Larsen et al., 2014; Abrams et al., 2016; Constable et al., 2016c, 2017; Trebilco et al., 2020; Cavanagh et al., 2021).

A threat to the sustainability of the toothfish fisheries was the rise of illegal, unreported and unregulated (IUU) fishing by longliners in the 1990s (Österblom et al., 2015). The catch from IUU fishing was estimated by CCAMLR according to catch rates of the legal fishery, the number of observed IUU longlining vessels and the expected time fishing. Concerted effort amongst CCAMLR Members to combat IUU fishing led to a substantial decline in the IUU fleet and in estimated total illegal catch by 2008 (Figure 7). IUU fishing still occurs at a low level but mainly using gillnets. The loss of fish to gill nets is difficult to measure, because observations of vessels cannot be readily translated to the amount of fishing effort and catch rates are difficult to assess. As a result, estimates of IUU catch have not been made since 2008.

A further threat to the toothfish fishery is the depredation of toothfish from longlines (Söffker et al., 2015; Tixier et al., 2016). This can impact the viability of the fishery but also affect the mortality of fish from the fishery; estimates of depredation are needed in order to correctly estimate how many fish have been removed from the stock.

The fishery for Antarctic krill was undertaken in the Atlantic, Central Indian and East Pacific Sectors in its first decade. 


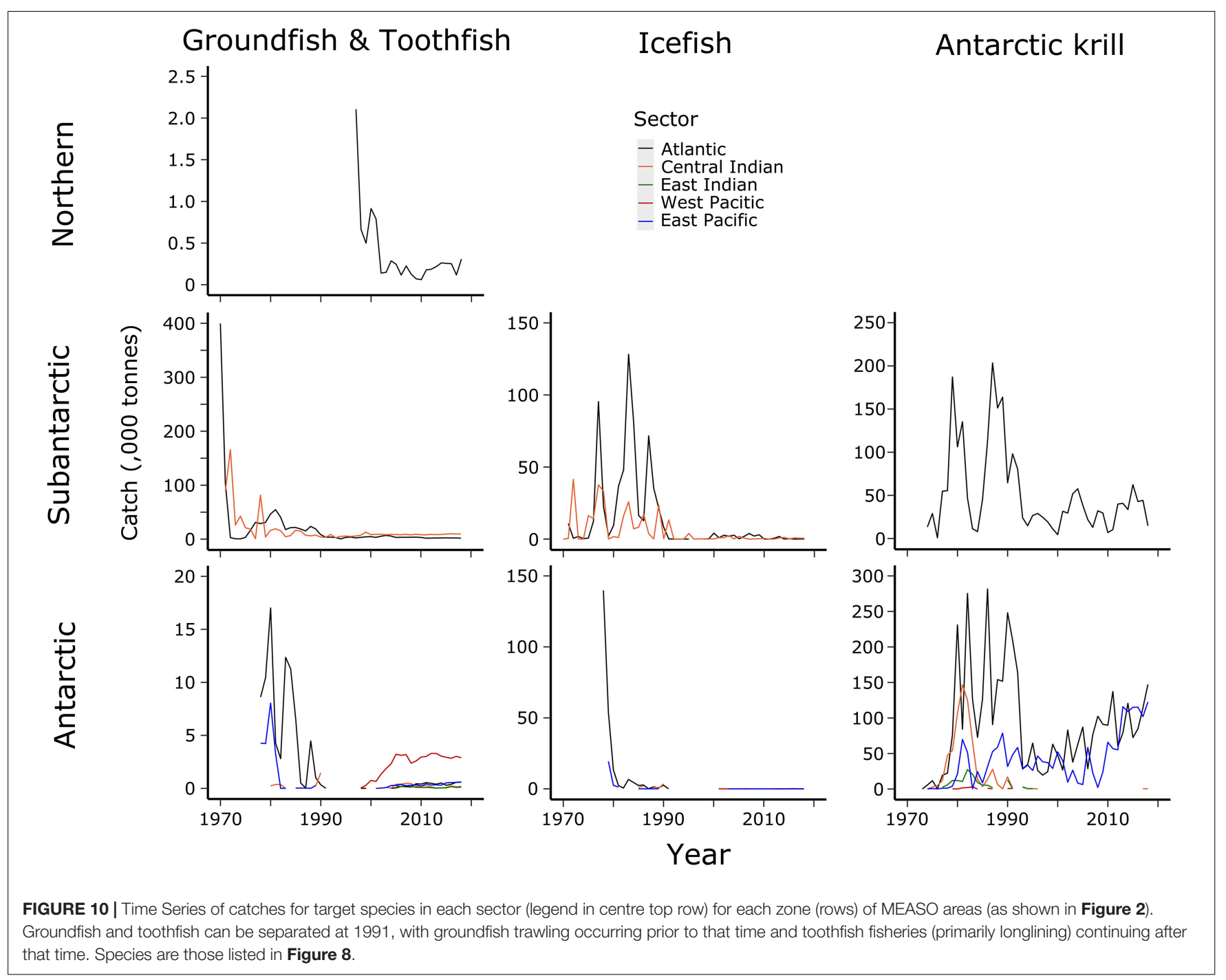

Since then, the fishery has concentrated on the west Antarctic Peninsula (South Shetland Islands and, more recently, Bransfield Strait) in the Antarctic Zone of the East Pacific Sector, and the South Orkney Islands in the Antarctic Zone and South Georgia in the Subantarctic Zone of the Atlantic Sector. After a decline in the krill fishery in 1991, the catch around South Georgia has remained relatively constant, while catches have steadily increased around the South Orkneys (Nicol and Foster, 2016). With increasing open water conditions extending the fishing season into winter, the Bransfield Strait has become a very important location for the fishery (Kawaguchi et al., 2009; Nicol and Foster, 2016). While the krill catch limits are considered sustainable for the krill population as a whole (Constable, 2011), there remains great potential for localised effects of krill harvesting on krill predators (Constable, 2002; Constable et al., 2017), even at the current levels of harvest (Watters et al., 2013, 2020) and particularly under scenarios of climate change (Klein et al., 2018). Recent developments to distribute catch inversely to localised risks to predators has advanced the regulatory approach for krill and could be used to help manage for climate change impacts on the ecosystem (Constable et al., 2016b).

Scope for new fisheries in the Southern Ocean remains primarily in relation to mesopelagic fish and Antarctic silverfish, both of which are important prey species in pelagic and coastal waters, respectively (Koubbi et al., 2017; McCarthy et al., 2019; Saunders et al., 2019).

\section{Incidental Mortality From Fisheries}

Incidental mortality from fisheries includes the unintentional catch or entanglement of other fish, seabirds and seals. It can also arise from impacts of fishing gears without capture, such as might occur through the impacts of bottom fishing gears on benthos.

CCAMLR has successfully developed measures to reduce seabird mortality in fishing to only an occasional event. Croxall (2008) describes the measures and strategies put in place from the early 1990s to eliminate systemic incidental mortality from CCAMLR fisheries. Soon after the start of longlining for toothfish began in the late 1980s (Figure 11), concern for the capture of seabirds in this fishery led to the development of methods 


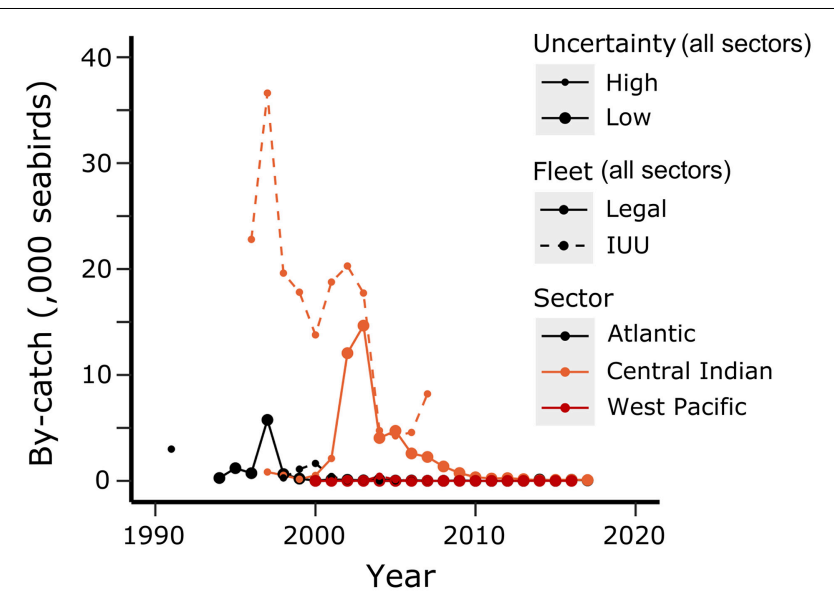

FIGURE 11 | Incidental mortality of seabirds estimated for trawl and longline fisheries (legal fleet; solid lines) and for illegal, unreported and unregulated fishing fisheries (IUU fleet; dashed lines) for each sector of the Southern Ocean (see Figure 2). Few birds are caught in the Antarctic Zone. Most are caught near to subantarctic islands. Data obtained from reports of the Scientific Committee of CCAMLR from 1994 to the present. Size of circle reflects the uncertainty in the estimates. Small circles reflect greater uncertainty - in IUU estimates these were labelled by SC-CAMLR as medians. Time-series of IUU estimates end in 2008; IUU fishing was low and vessels used gill nets and catches could not be estimated. to deter seabirds from attacking baits during deployment and for deterring birds from approaching the gear during hauling. These methods included weighting longlines as well as deploying streamer lines. Strategies included having requirements for scientific observers on fishing vessels to monitor bird interactions with fishing gear and by restricting fishing from seabird foraging areas during the bird breeding season. IUU longline fishing vessels were likely to have had a great impact on seabirds during the height of IUU fishing over the decade from 1997 to 2007 (Figure 11). While seabird mortality in CCAMLR fisheries remains low, incidental mortality of Southern Ocean seabirds in longline fisheries outside of the CCAMLR Area remains a great risk to the conservation of some of these species (Clay et al., 2019).

The potential for bottom fisheries, notably trawling, to have significant long-lasting effects on benthic habitats and communities came to the attention of CCAMLR in 2006 (SCCAMLR, 2006) and measures were taken in 2007 to conserve vulnerable marine ecosystems (VMEs). While CCAMLR established a Conservation Measure to prohibit bottom trawling in high seas areas in CCAMLR it also established measures to protect VMEs from demersal longlining with provisions to move on from areas where high biomass (defined as two buckets) of habitat-forming taxa were observed as bycatch in an individual longline shot (CCAMLR, 2007, 2008). Figure 12 shows the overall fishing effort as effort density for bottom trawling (hours) and longlining (hooks) given the available effort data from the CCAMLR Statistical Bulletin CCAMLR (2019).

Scaling the effort to the level of disturbance of the seafloor, also known as the fishing footprint, is best done using haul data, including the location of each haul and, in the case of trawls, the swept area of the net (width of the opening of the net combined with the distance towed) and, for longlines, the swept area of the line, which is the amount of sideways movement of the line during its deployment, fishing and retrieval. These data are not available in the Bulletin. In the absence of those data, we examine the effort density per $\mathrm{km}^{2}$ and use information from Welsford et al. (2014) on the characteristics of trawl and longline hauls to consider the proportion of seabed that might have been affected. We note that the densities in Figure $\mathbf{1 2}$ may be lower than as experienced in local areas because of the method of evenly distributing the effort throughout depth range of a fishery in an area. In addition, localised concentrations may also reduce the effects because of repeated disturbance of the same area.

Effort densities in both trawl and longline fisheries were highest in the Subantarctic Zone in both the Atlantic and Central Indian Sectors. Trawling also had high effort densities in the Antarctic Zone of the East Pacific and Atlantic sectors, from trawling prior to CCAMLR around the Antarctic Peninsula and the islands of the Scotia Sea. Longline effort in the Antarctic Zone has been greatest in the West Pacific Sector associated with the Ross Sea fishery. The only bottom trawl fishery now in operation is at Heard Island. This has been assessed to be localised and not significantly impacting the benthic environment, part of which is due to the presence of the nearby marine protected area (Constable and Welsford, 2011; Welsford et al., 2014; Brooks C.M. et al., 2019).

The greatest accumulated recorded effort for trawling has been a density of $3.1 \mathrm{~h}$ per $\mathrm{km}^{2}$. $(\log 10=0.491)$ (noting the absence of records for the very large catches). For longlining, the greatest accumulated density has been 11,000 hooks per $\mathrm{km}^{2}$ $(\log 10=4.04)$. Using the mean estimates of swept areas for trawl gear $(20 \mathrm{~m})$ and longlines $(6.2 \mathrm{~m})$ from Welsford et al. (2014) and assuming trawling was undertaken at a conservative speed of 2 knots, this equates to the proportion of seabed area affected as $23 \%$ and $6.8 \%$, respectively.

A shortcoming of the current analysis is the lack of availability of geolocated haul data. Nevertheless, our analyses indicate that the magnitude of impact is unlikely to be trivial at a local scale, if the fisheries are concentrating in sensitive benthic areas. Welsford et al. (2014) provide methods for using geolocated haul data, along with camera deployments on fishing gear, for assessing the direct impacts of fisheries on benthic habitats.

At present, CCAMLR has a process for registering VME locations and providing interim protection to areas identified as possible VMEs, known as risk areas, during longline operations $\left(\right.$ CCAMLR VME registry ${ }^{4}$ ). At present (accessed October 25, 2020), it has 53 locations registered as VMEs across the west Antarctic Peninsula, South Orkneys, Ross Sea and East Antarctica. For risk areas identified during fishing, seventy seven areas have been identified in the Ross Sea and one in East Antarctica. There is yet to be a follow-up evaluation of the nature and extent of those sensitive areas, which may be larger than the circumscribed locations.

\footnotetext{
${ }^{4}$ https://www.ccamlr.org/en/document/data/ccamlr-vme-registry
} 


\section{Trawling}
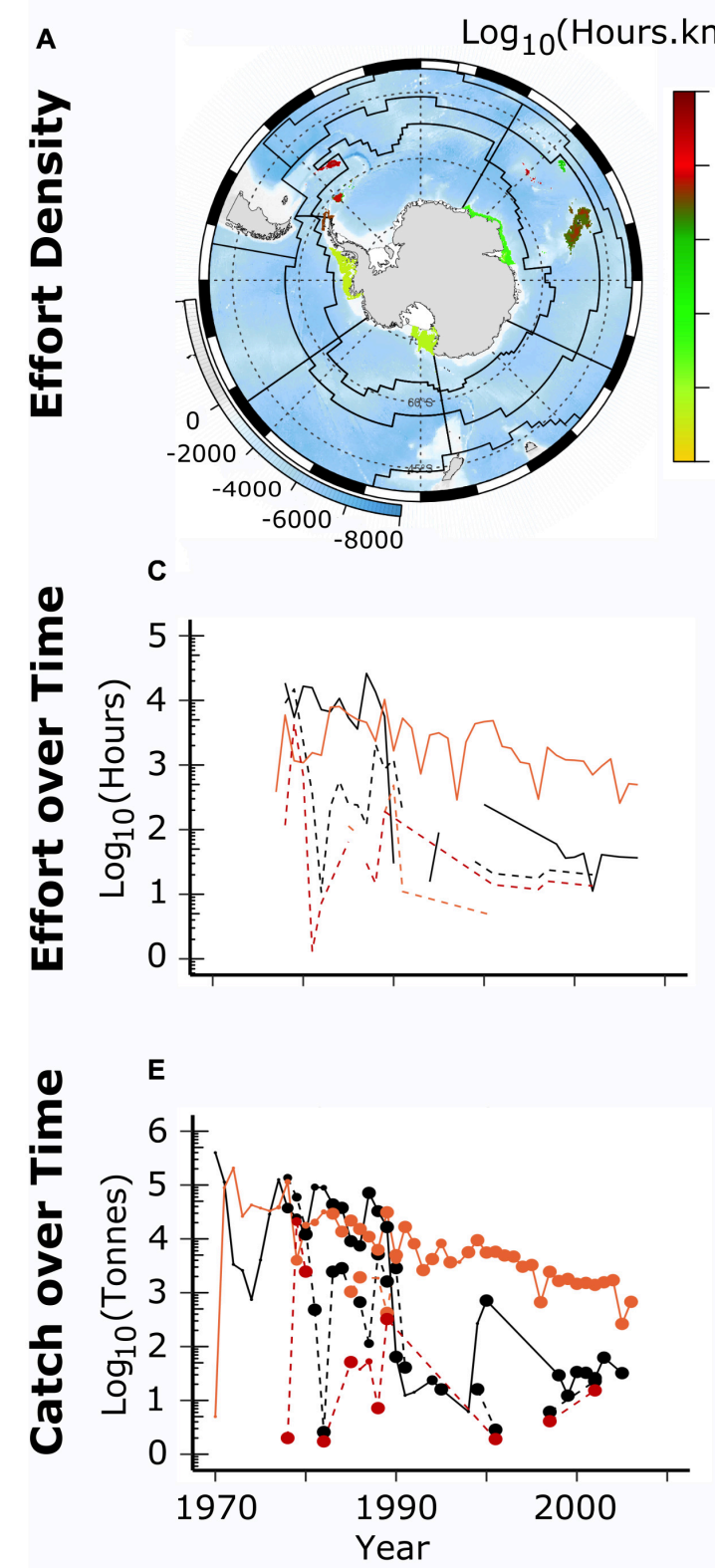

\section{Longlining}

B $\quad \log _{10}\left(\right.$ Hooks. km ${ }^{-2}$ )

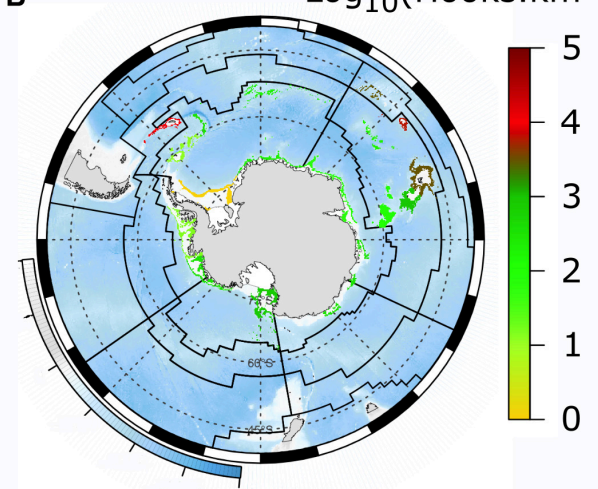

D

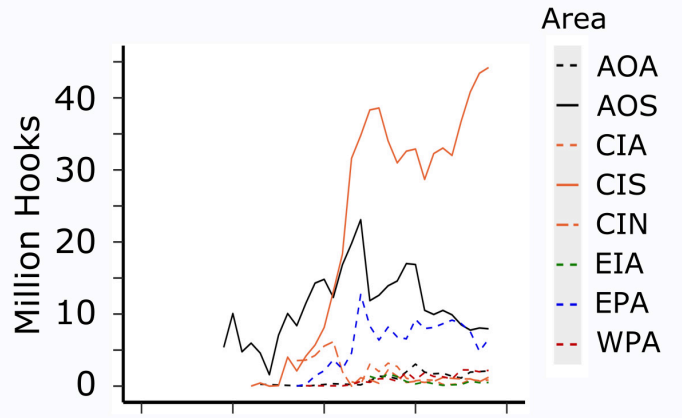

$\mathbf{F}$

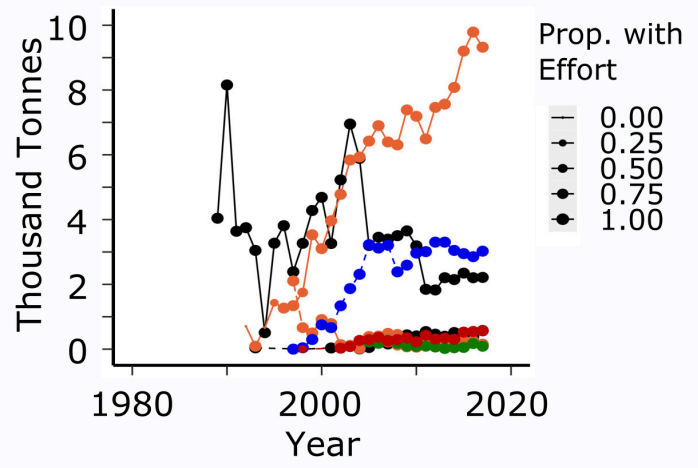

FIGURE 12 | Bottom fishing effort in MEASO areas for trawl and longline fisheries. Top row (A,B) shows effort density per km² - hours and hooks, respectively, on a log10 scale. Background is ocean depth (bottom left legend on each map). Black lines show boundaries of MEASO areas as depicted in Figure 2. Middle row (C,D) shows effort over time (split year) in each MEASO area according to the legend at right where labels indicate the sectors (first two letters) and zones (last letter) for each area. Sectors are Atlantic (AO), Central Indian (CI), East Indian (El), West Pacific (WP), and East Pacific (EA). Zones are Antarctic (A), Subantarctic (S), and Northern (N). Bottom row (E,F) shows the time series of catches in each area - colour and line types according to the middle row legend. Catches are the total catch of targeted species in bottom fisheries (groundfish, icefish, and toothfish). Circle size indicates the proportion of the catch that had effort data associated with it.

\section{Recovery of Marine Mammals}

Exploitation and recovery of marine mammals has been widespread (Rocha et al., 2014). Here we focus on marine mammal recovery in the MEASO areas that have experienced most human impact; broader trends are reviewed by Bestley et al. (2020).
Following protection from exploitation, many marine mammal species are now recovering, with surveys showing growth, for example, in populations of humpback (Branch, 2011; Ward et al., 2011; Noad et al., 2019), southern right (Cooke et al., 2001; Carroll et al., 2013) and Antarctic blue whales (Branch et al., 2004), all of which seasonally feed in Southern Ocean 
waters. As these whales, and some seal species such as fur and crabeater seals, are krill consumers; at a local scale increases in marine mammal abundance may be anticipated to influence krill swarms (Cox et al., 2009; Ducklow et al., 2013), and also influence oceanic nutrient enrichment and mixing (Lavery et al., 2014; Roman et al., 2014).

Krill swarms of different sizes and densities are differentially predated by different whale species (Cox et al., 2009; Santora et al., 2010, 2014; Friedlaender et al., 2014; Miller et al., 2019) due to their varying sizes, morphology and energetic requirements. Reductions in local krill abundance could reduce food available to more area-restricted central place foragers such as breeding penguins and seals. For example, a spatial study of multiple krill predators, using canyon waters near Livingstone Island, suggested an overlap between humpback whales and penguins which would support this idea (Santora and Reiss, 2011). Any reductions may be compounded by local krill fishing, particularly in the Antarctic Peninsula region where this activity is concentrated (Kawaguchi and Nicol, 2020) and partially coincident with the peak period when whales visit (Weinstein et al., 2017). However, prey competition is not necessarily the obvious outcome of whale presence, as whales are less spatially restricted than the central place foragers, may have differing krill swarm preferences (Friedlaender et al., 2009, 2016) and may even modify krill swarm behaviour (e.g., Cox et al., 2009). For example, it is most energetically efficient for whales to target the densest prey patches (Acevedo-Gutierrez et al., 2002; Goldbogen et al., 2011; Friedlaender et al., 2015), while smaller krill predators may be less restricted in their preference. The impact of whale foraging on krill swarm behaviour is also hard to predict; whale predation may, for example, change krill swarming behaviour in ways that make them more accessible to other predators, for example by dispersing high density krill swarms, or by bringing krill closer to the surface.

A second, widely discussed, possible impact of whale recovery concerns their role within the ecosystem as a biological pump, moving nutrients from deep waters to surface waters as they dive to forage, and enhancing surface water nitrogen and iron (and therefore primary productivity) in "pulses," through defecation in surface water (Lavery et al., 2014; Ratnarajah et al., 2014; Roman et al., 2014). Consequently, whales may initiate a positive feedback loop, where the productive places that they go to feed are then further enhanced in terms of primary productivity, because of their presence (Roman et al., 2014). This may be particularly pronounced in enclosed areas such as bays, where current flows are limited. There are widespread, strong and important biotabiogeochemistry interactions in Southern Ocean waters, near and offshore, from megabenthos through to microbes (Cavan et al., 2019; Henley et al., 2020).

In the western Antarctic Peninsula, high densities of humpback whales seasonally feed on krill in the Gerlache Strait and bays of the Peninsula (Nowacek et al., 2011; Johnston et al., 2012). There are no empirical abundance trends available for this population (which seasonally winters in the Pacific waters of central and south America). Model-based estimates using historical catch data suggest the population is close to carrying capacity (IWC, 2016), but high levels of female pregnancy detected within this population $(63.5 \%$ of females, including mothers with calves, Pallin et al., 2018) suggest that it is still growing. Less is known about the abundance trajectories of other regionally important species; Antarctic blue whale numbers are thought to be increasing further offshore in the Peninsula region based on sighting surveys (Branch, 2007), but since they range widely (Branch et al., 2007), population changes may not be particularly concentrated in local waters. Antarctic minke whales can be locally abundant, but were not heavily exploited during the main commercial whaling period, and there is no evidence that their numbers are increasing locally; if anything, recent surveys suggest a $60 \%$ decline over the decade spanning the 1990s (IWC, 2013).

More than 170,000 whales were killed in South Georgia waters, indicating the historical importance of whales at a local scale within this ecosystem (Moore et al., 1999). Anecdotallyreported humpback sightings have risen rapidly in the last decade (Jackson et al., 2015, 2020), consistent with recent assessment that this humpback whale population is now close to recovery from whaling (Zerbini et al., 2019). Formal assessments are not available for other species, but southern right whales are regularly seen (Moore et al., 1999) and there has been steady 6-7\% per annum population growth in the Argentine southern right whale calving ground seasonally associated with South Georgia (Cooke et al., 2001). There are also increasing reports of blue whales using South Georgia shelf waters, suggesting some regional recovery (Calderan et al., 2020). The impacts of these changes might mean increased competition for krill with other predators, but these may be balanced by positive benefits from the impact of whales on krill swarms, if whale predation makes them more available to smaller krill predators. Furthermore, as the South Georgia krill fishery operates only during winter, human impacts are minimal during the peak period of whale occurrence.

\section{Coastal Change/lce Loss and Iceberg Scour}

Until recently, climate mediated-marine ice loss in the Southern Ocean was mostly restricted to West Antarctica, but this is now also rapidly occurring throughout East Antarctic seas (Turner and Comiso, 2017). One of the ways in which marine ice is being lost is increased iceberg calving (from ice shelf collapses and glacier retreat). Reduced seasonal freezing of the sea surface in space and time means that such icebergs are less likely to be locked into one location, so the potential of iceberg movement is also increasing (see Smale et al., 2008). Increased iceberg numbers and mobility drives a higher probability and frequency of collisions with the seabed and massive disruptions to benthic biodiversity (Gutt, 2001; Barnes and Souster, 2011). Monitoring of scouring in the productive shallows at Rothera (Barnes, 2017) and Carlini research stations (Deregibus et al., 2017) has shown that two thirds of life shallower than $25 \mathrm{~m}$ depth may be wiped out in some years at some locations.

Iceberg scouring decreases markedly with depth, but certain hotspots are regularly impacted even at several hundred meters depth. Large icebergs, tracked via earth observation satellites, have distinct geographic hotspots of grounding, including the East Amundsen Sea in West Antarctica, and the narrow shelf of the Davis and Cosmonaut Seas and Cape Norvegia (East Weddell sea) (see Barnes et al., 2018). Thus, although marine 
ice losses are driven by global processes (warming) and have many similarly large influences (e.g., heat and gas exchange), the effect on biodiversity can be quite localised and predictable. Many local areas of iceberg production are likely to gain considerable biodiversity and ecosystem services, for example bays emerging from ice shelf collapses and fjords from glacier retreat (Cavanagh et al., 2021). In contrast, iceberg collision hotspots, such as in the Weddell Sea could lose biodiversity, but there seem to be more blue carbon winners than losers with marine ice loss so far (Barnes et al., 2018). However, it is harder to assess how well Southern Ocean biodiversity will be resilient to the breadth and complexity of stressors, many of which interact, especially on the seabed where we know least, yet most known species occur (Brasier et al., 2021; Zwerschke et al., 2021).

Other global drivers, such as strengthening of winds due to ozone loss, are likely to interact with sea ice changes, for example, in the generation and maintenance of polynyas, and thus influencing primary production (see Arrigo et al., 2008). Recent evidence suggests that moderate sea temperature increases in Antarctica's shallows may increase colonisation and growth in new pioneers (Ashton et al., 2017), thus promoting recovery from ice scour. However, new habitat emerging from glaciers and ice shelves, longer periods of food availability (plankton blooms) and fast growth rates (temperature) are balanced with more ice scour, freshwater input and sediment loading from retreating glaciers, with highly localised but substantial negative impacts (Sahade et al., 2015). The impacts of these many interacting climate-forced variables are difficult to predict with perhaps 'boom and bust cycles' in many nearshore locations, but at least initially there may be more winners than losers (Morley et al., 2019).

\section{PROGNOSES AND PRIORITIES FOR THE FUTURE}

In assessing the projected increase or decrease of the influence of local drivers within MEASO areas (summarised in Table 1), we identified that the influence on Southern Ocean ecosystems of non-indigenous species, fishing, and the recovery of marine mammals are predicted (with medium to high confidence) to increase in the future across all MEASO areas. Fishing and the recovery of marine mammals have the potential to cause ecosystem impacts at the regional or ocean basin scale, as a result of their influences on foodwebs and nutrient cycling. The impacts of these drivers particularly on other marine predators are uncertain given the potential additive effects of fishing, marine mammal recovery and climate change.

The establishment of marine non-indigenous species could have similarly extensive, although unpredictable, ecosystem impacts. While there are currently very few records of nonindigenous species becoming established in the Southern Ocean, increased influence of this driver is predicted (high confidence) in the Antarctic Peninsula region and at sub-Antarctic islands, because of the elevated risks from increasing ship traffic and visitation, regional warming and sea ice losses.

The impacts of local, land-derived pollution are currently low, and this is the only driver identified here which is projected (low confidence) to decrease in some locations where historical infrastructure has been removed or is no longer in use. However, there is potential for some increase in land-derived pollution (medium confidence) with the further development of research station infrastructure and human visits to Antarctica and subAntarctic islands, as well as expanded geographic reach following the exposure of more ice-free ground. With the exception of severe incidents such as large oil spills, most point-source pollution influences very small local areas (in comparison to other types of pollution originating from outside the Southern Ocean such as the atmospheric or oceanic transport of POPs), and the most vulnerable habitats are therefore likely to be those in the vicinity of research stations. Areas such as James Ross Island, the coast of East Antarctica and the Ross Sea have seen an increase in station numbers, and while improvements in technology and management have reduced the risk of pollution, the potential for inadvertent fuel spills or other unintended consequences increases with increased national operator activity.

Marine-derived pollution is predicted (medium confidence) to increase across most MEASO areas except for those with the lowest levels of ship traffic associated with fishing, research or tourism. Much of this is attributed to the increasing amounts of plastics discovered in marine ecosystems (although coverage of observers and observations has also increased), however, a large proportion is likely to originate from outside the Southern Ocean, given the relatively low numbers of vessels and potential sources (Waller et al., 2017; Horton and Barnes, 2020). The potential impact of marine-derived pollution will increase with additional shipping, particularly in areas of concentrated tourism or scientific research, and where these activities overlap.

Recent trends relating to tourism in the Southern Ocean indicate a projected increase in numbers and diversity of activities in the future (high confidence), although this has almost certainly been slowed in the short to medium term by the global impacts of the Covid-19 pandemic. Visitors to Antarctica also include scientific researchers and logistics operators, who may similarly visit wildlife colonies and undertake other activities with the potential to cause disturbance. In areas such as the Antarctic Peninsula where ship traffic is most concentrated, ship strikes and disturbance impact on recovering marine mammal populations are anticipated to increase (medium confidence).

Changes to coastal areas as a result of ice loss are also driven by global processes (particularly warming), but have local influences on biodiversity which can be predicted with a high level of confidence, particularly in areas experiencing most rapid warming such as the Antarctic Peninsula and South Georgia. Increased iceberg scour has a direct effect on seafloor communities, while marine and terrestrial areas that are exposed following glacial retreat or ice shelf collapse may provide new habitat for the establishment or spread of non-indigenous species.

The majority of the local drivers identified in Table $\mathbf{1}$ are projected to increase or remain at similar levels of influence into the future, indicating that management of these drivers, particularly where they relate to local human activities, is critical. The interaction of all local drivers with each other or with global drivers also demonstrates the importance of such management being developed with integrated consideration of globally-driven 
TABLE 1 | Assessment of the projected increase (+) or decrease (-) of the influence of local drivers within MEASO areas (based on information provided in the previous sections).

\section{MEASO area}

(defined in

Figure 3)

\section{DRIVER}

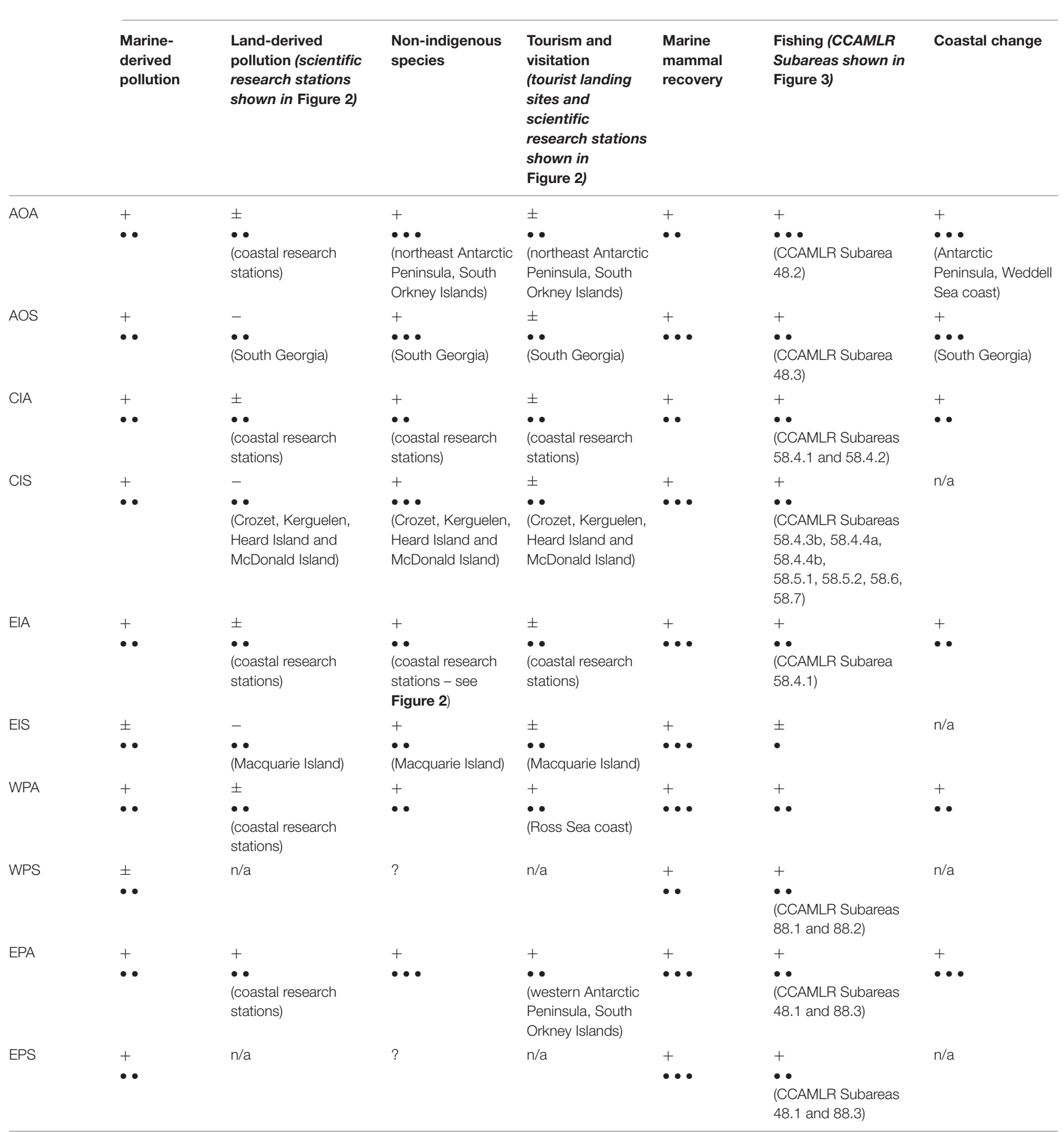

\pm indicates no change; ? indicates no information, and n/a indicates that the driver is not relevant in that area. Black dots indicate the level of confidence (low confidence, medium confidence, high confidence). Local drivers may not have an influence across all of a given area; where this is the case, locations in brackets identify where the influence is greatest. 
environmental change. Global human population growth will increase the demand for SO ecosystem services into the future, particularly provisioning services (fishing), but also tourism and the scientific or cultural value of marine biodiversity (Rogers et al., 2020; Cavanagh et al., 2021).

\section{POLICY IMPLICATIONS}

Local drivers can be controlled or mitigated, to varying degrees, by the implementation of conservation measures, regulations and guidelines under the instruments of the Antarctic Treaty System and other international governance organisations. In contrast, the regulation of global drivers such as increasing temperature, ocean acidification and sea ice change will require global policy action, such as the implementation of the United Nations Framework Convention on Climate Change (UNFCCC) Paris Agreement, and associated efforts to regulate human activities at national levels. Restrictions on human activities within the Southern Ocean (e.g., fisheries management, regulation of tourism, and establishing protected areas) are important in addressing local and regional drivers, and thus minimising cumulative impacts on Southern Ocean ecosystems, but will have little or no effect on the impacts of global drivers, which may be much more significant. Understanding the interactions between local drivers, and with global drivers, is therefore important for the design of effective policy responses. Management actions taken on individual drivers may affect other drivers, with potentially unintended consequences, therefore an ecosystem-based and integrated approach to management is critical (Millennium Ecosystem Assessment, 2005).

As far as possible, management actions should be informed by comprehensive and accessible information on the status and trends of marine biodiversity and human activities, and particularly the current and projected influence of local drivers. Box 1 identifies some of the major research gaps and priorities that would help to enhance the information summarised in Table 1, and improve the foundations for management decisionmaking.

Table 2 identifies regulatory frameworks which have established conservation and management measures relevant to specific local drivers. The instruments of the ATS, including CCAMLR and the Protocol on Environmental Protection, form a comprehensive framework allowing for the regulation of fishing, tourism, and impacts associated with human activities including pollution and the introduction of non-indigenous species. Maintenance of the ATS is key to ensuring the ongoing limitation of negative impacts from local drivers on Southern Ocean ecosystems. However, continuing enhancement of its conservation and management approaches is also important, as current tools and frameworks may not be adequate to address future changes to local drivers, or to effectively consider the effects of multiple drivers in the context of climate change.

The Protocol provides general principles of environmental protection applicable to the Antarctic Treaty areas (the area south of latitude $60^{\circ} \mathrm{S}$ ), notably through designation of the continent as a 'natural reserve, devoted to peace and science.' However, the more detailed provisions described in
BOX 1 | Research gaps and priorities.

Projections of future changes in the influence and extent of local drivers in the Southern Ocean are heavily dependent on an improved understanding of how global drivers such as climate change will affect Southern Ocean ecosystems. The interaction between global and local drivers, such as the consequences of a changing climate for recovering marine mammal populations or for the potential establishment and spread of non-indigenous species, remains poorly understood. It is important to differentiate between trends that are the result of natural environmental variability and those that are anthropogenic or the result of climate change. Fishing and tourism are both ultimately controlled by global markets, and uncertainty about future economic constraints and demand for these services could also make their trajectories difficult to predict. Geopolitical uncertainty may be a further limitation on projections of future change, since changes to the Antarctic Treaty System could lead to the weakening of environmental and fishery regulations, and a corresponding increase in the negative impacts of human activities.

Key information requirements for identifying and managing risks to the Southern Ocean environment associated with local drivers include:

- Identification of local sources of pollutants (especially POPs and microplastics), and mechanisms of transport and accumulation.

- Assessment and monitoring of impacts associated with tourism and other visits.

- Conditions for establishment and rates of spread of marine non-indigenous species.

- Krill biomass and distribution in both fished and unfished areas.

- Vulnerability of marine species and habitats to the effects of all human activities (including local and global drivers).

- Projected responses of krill-dependent predators to fishing and climate change.

- Status of Southern Ocean cetacean populations and regional projections of recovery and consumption.

- Changes to the distribution of ice-free coastal areas and associated marine impacts. While local drivers are concentrated at sites visited by humans, these are also the sites that are most likely to be monitored, although comprehensive monitoring of any site has yet to be achieved. Information from other more remote sites will help to assess the extent to which these influences impact other areas within the MEASO region (although teleconnections to these remote locations, especially from populated areas to the north of the MEASO region, could cause unexpected influences). The coverage of in situ monitoring can be improved to some extent by remote observations, for example, satellite remote sensing to monitor coastal change and marine mammal abundance changes, time-lapse cameras to observe breeding success in wildlife colonies, and moorings or autonomous vehicles to obtain oceanographic and acoustic data. The establishment of longer time-series may be required in order to detect trends, and increasing data collection may also require increasing capacity for analysis. New mechanisms to integrate data, for example, using Essential Ocean Variables (EOVs), and to coordinate efforts and data sharing between existing programmes, such as through the Southern Ocean Observing System (SOOS), aim to provide ecosystem information that is accessible to decision-makers (Constable et al., 2016a; Benson et al., 2018; Newman et al., 2019). Ecosystem modelling may also facilitate better understanding of ecosystem processes such as predator-prey interactions and population dynamics, or considerations of how global and local drivers might affect species and foodwebs (Hill et al., 2006; Klein et al., 2018). Fishing vessels provide a large amount of information relevant for fisheries management, through the CCAMLR Scheme of International Scientific Observation (SISO), as well as direct involvement in the collection of data such as acoustic surveys and fish tagging. In recent years, the industry bodies ARK (Association of Responsible Krill harvesting companies) and COLTO (Coalition of Legal Toothfish Operators) have been increasingly engaged in discussions within CCAMLR on further developing fishing industry contributions to data collection. Continued efforts to utilise fishing vessels as scientific research platforms will be valuable in providing the data needed to improve fisheries management (Meyer et al., 2020). Efforts to improve the provision of information relating to local drivers would benefit from clear guidance on the specific information required by ATS bodies to inform management decisions.

(Continued) 
BOX 1 | Continued

Improved practical co-operation between different groups involved in Southern Ocean management, primarily CCAMLR and the CEP, but also CCAMLR and the IWC, as well as ACAP, would also have significant benefits in terms of broadening the availability of relevant information, and facilitating the development of comprehensive and more strategic management approaches.

the five Annexes to the Protocol that have so far entered into force, are in most cases now almost 30 years old. Consequently, in most cases there is scope for revision and/or provision of additional guidance detailing potentially higher environmental standards and/or use of new technologies, as now common within many other regions of the planet. For example, impacts in the marine environment from sewage disposal could be reduced through the increased use of sewage treatment plants, including agreed minimum effluent quality standards. Policy development could include improvements in the Environmental Impact Assessment process, more stringent regulation of vessels to reduce the risk of introduction of marine species (particularly on vessel hulls), more comprehensive regulation of tourism activities, and more strategic planning for the implementation of the protected areas system including the adequate protection of vulnerable and/or representative near shore environments, as well as coastal locations accommodating concentrations of Antarctic wildlife. Nevertheless, there is a concern that the pace of change in Antarctic environments and of the level and scope of human activity in the region is not being matched by the pace of development of necessary environmental policy (Hughes et al., 2018).

Effective fisheries management requires an understanding of current and projected impacts from both local and global drivers on target species and associated and dependent species. Consideration of global drivers (climate change, as well as potential socio-economic drivers in terms of demand for ecosystem services, see Cavanagh et al., 2021) must be integrated into management decision-making. As a conservation-focussed body and an integral part of the ATS, CCAMLR differs from Regional Fisheries Management Organisations (RFMOs) in that it is able to address broader objectives of ecosystem conservation. CCAMLR's principles of conservation (Article II of the Convention) include preventing the decrease of harvested populations below levels that ensure their sustainable recruitment; maintenance of the ecological relationships between harvested, dependent and related populations of Antarctic marine living resources; and prevention of changes in the marine ecosystem which are not potentially reversible over two or three decades. Such precautionary approaches should include the spatial distribution of krill catch limits to prevent local impacts on predator populations, as part of the risk assessment and revised krill management strategy currently being developed by CCAMLR (Watters et al., 2013; Hill et al., 2016). Cooperation on data sharing, particularly between CCAMLR and the IWC on ecosystem modelling and consideration of cetacean population changes and krill consumption levels, would be a valuable contribution to this work.

TABLE 2 | Regulatory frameworks establishing measures relevant to specific local drivers.

\begin{tabular}{|c|c|c|}
\hline $\begin{array}{l}\text { Local } \\
\text { driver }\end{array}$ & $\begin{array}{l}\text { Regulatory } \\
\text { framework }\end{array}$ & $\begin{array}{l}\text { Existing measures to limit drivers } \\
\text { or mitigate their impacts }\end{array}$ \\
\hline $\begin{array}{l}\text { Marine- } \\
\text { derived } \\
\text { pollution }\end{array}$ & $\begin{array}{l}\text { Protocol on } \\
\text { Environmental } \\
\text { Protection to the } \\
\text { Antarctic Treaty. } \\
\text { CCAMLR. } \\
\text { International Maritime } \\
\text { Organisation (IMO). }\end{array}$ & $\begin{array}{l}\text { Annex III (Waste disposal and waste } \\
\text { management) and Annex IV } \\
\text { (Prevention of marine pollution). } \\
\text { Conservation Measure } 26-01 \text { on } \\
\text { General environmental protection } \\
\text { during fishing (including disposal of } \\
\text { plastics). } \\
\text { MARPOL Annex V on the Prevention of } \\
\text { Pollution by Garbage from Ships. } \\
\text { International Code for Ships Operating } \\
\text { in Polar Waters. }\end{array}$ \\
\hline
\end{tabular}

$\begin{array}{lll}\text { Land- } & \text { Protocol on } & \text { Annex I (Environmental Impact } \\ \text { derived } & \text { Environmental } & \text { Assessment) and Annex III (Waste } \\ \text { pollution } & \text { Protection to the } & \text { disposal and waste management). }\end{array}$

pollution Protection to the Antarctic Treaty.

$\begin{array}{ll}\text { Tourism } & \text { Antarctic Treaty. } \\ \text { and } & \text { Protocol on } \\ \text { visitation } & \text { Environmental } \\ & \text { Protection to the } \\ & \text { Antarctic Treaty. }\end{array}$

\section{Non- Antarctic Treaty. indigenous Protocol on species Environmental Protection to the Antarctic Treaty. CCAMLR. IMO}

Fishing CCAMLR. Regional Fisheries Management Organisations (RFMOs) adjacent to the CCAMLR Area. Agreement on the Conservation of Albatrosses and Petrels (ACAP).

Recovery of CCAMLR. marine IWC. mammals

\section{Coastal CCAMLR}

change

\section{Resolution X (2011) on Guidelines for Visitors to the Antarctic. Visitor Site Guidelines (specific instructions on the conduct of activities at the most frequently visited Antarctic sites). \\ Environmental Protocol Annex V (Area protection and management) - designation of Antarctic Specially Protected Areas (ASPAs) and Antarctic Specially Managed Areas (ASMAs). \\ Resolution X (2011) on Guidelines for Visitors to the Antarctic. \\ Committee on Environmental Protection Non-Native Species Manual. \\ Resolution 28/XXVII on Ballast water exchange in the Convention Area. International Code for Ships Operating in Polar Waters.}

Conservation Measures establishing: catch limits, open and closed areas, gear restrictions, reporting requirements, bycatch limits, minimisation of incidental mortality, open and closed seasons, and protected areas (including MPAs). Management of fish stocks adjacent to the CCAMLR Area, mitigation of bycatch and incidental mortality. Mitigation of incidental mortality of seabirds, including outside the CCAMLR Area.

Krill fishery management strategy inclusion of cetaceans in the risk assessment framework to inform spatial allocation of krill catch. Population assessments of whale recovery; formal review and validation of regional abundance and trend estimates.

Conservation Measure 24-04 on establishing Special Areas for Scientific Study in newly-exposed marine areas following ice shelf retreat or collapse. 
In addition to fishery-specific measures, CCAMLR also has a mandate to implement marine protected areas (MPAs) with objectives including the conservation of biodiversity, establishment of scientific reference areas, protection of areas vulnerable to the impacts of human activities, and of areas to maintain resilience to climate change (CCAMLR Conservation Measure 91-04). While progress toward CCAMLR's agreed objective to establish a representative system of MPAs has been limited to date, the adoption of a suite of additional areas currently under negotiation would substantially improve the representation of Southern Ocean biodiversity in protected areas (Brooks et al., 2020). Antarctic Specially Protected Areas (ASPAs) can also be implemented in marine areas under the Protocol on Environmental Protection, and could be nested within MPAs or established in complementary areas as part of a more strategic approach to the conservation of marine ecosystems across both CCAMLR and the CEP. Localised conservation and management actions such as MPAs, ASPAs or VME designations could also act as a driver of recovery for marine ecosystems, by reducing or removing other drivers that have previously resulted in negative impacts, for example, the recovery of locally impacted benthic habitats following closure to fishing (considered in Brasier et al., 2021).

The interaction between CCAMLR and the CEP also has an important role to play in identifying and progressing issues of common interest with regard to local drivers. For activities which affect the marine environment, cross-over responsibilities are established within the respective conventions, for example to ensure that all CCAMLR Members acknowledge the special obligations and responsibilities of the Antarctic Treaty Consultative Parties for the protection and preservation of the environment of the Antarctic Treaty area (CCAMLR Convention, Article V), and to provide for CCAMLR approval of marine Antarctic Specially Protected Areas (Environmental Protocol, Annex V). Joint workshops have also agreed customary practices establishing which body will 'lead' on topics such as non-native marine species (CEP) and marine spatial protection (CCAMLR) (ATCM, 2009), while cooperation on climate change and monitoring was the focus of the most recent joint CEP and CCAMLR Scientific Committee discussions (CCAMLR, 2016). Although not yet implemented to their full potential, the range of tools available across CCAMLR and the Environmental Protocol, particularly on spatial protection, should allow for comprehensive systems of marine protection and management to be established in the Southern Ocean, tailored to the specific requirements of different regions and human activities.

Additional global frameworks such as the International Maritime Organisation (IMO) provide additional measures that apply to all vessels in the Southern Ocean, particularly through the International Code for Ships Operating in Polar Waters. Adjacent RFMOs ${ }^{5}$ can also implement measures that may reduce impacts on Southern Ocean species (for example bycatch mitigation measures to protect highly migratory

${ }^{5}$ RFMOs adjacent to the CCAMLR Area are: South-East Atlantic Fisheries Organisation (SEAFO), South Indian Ocean Fisheries Agreement (SIOFA), South Pacific Regional Fisheries Management Organisation (SPRFMO), Commission for the Conservation of Southern Bluefin Tuna (CCSBT). seabirds, and controls on discarding fishing gear). However, cooperation between CCAMLR and neighbouring RFMOs would benefit from improved communication, and data-sharing to address changes in stock structure, by-catch and environmental and climate change impacts (CCAMLR Performance Review, CCAMLR, 2017).

Integrated management across the ATS and related instruments is needed to address the specific impacts of local drivers in the context of broader environmental conditions, particularly in relation to climate-related change. Such management will be most effective where it is informed by robust scientific information and projections of change, and new innovations (particularly in modelling and remote observations) will help to provide this. However, there is also a need for precautionary measures to ensure that risks are minimised, especially where data are limited or when confidence in projections of the nature and extent of the impacts of drivers on biota is low. Although heavily impacted by historic exploitation of marine species, the Southern Ocean remains less affected by current local drivers of change such as pollution and fishing than much of the rest of the global ocean. The unique governance frameworks of the Antarctic Treaty System provide the means to ensure that this status is maintained into the future.

\section{AUTHOR CONTRIBUTIONS}

SG and CLW outlined the manuscript and coordinated text contributions. SG, AC, DB, MB, MD, KH, JJ, and CMW contributed text on individual sections. SG and CLW designed Figures 1, 3 which were produced with assistance from $\mathrm{HG}$, Stacey McCormack and the MEASO Support Group. AC produced Figures 2, 4-12. SG and SM developed Tables 1, 2 with input from all authors. All authors contributed to development and revision of the manuscript.

\section{ACKNOWLEDGMENTS}

This work is a core contribution to the first Marine Ecosystem Assessment for the Southern Ocean (MEASO), part of the Integrated Marine Biosphere Research (IMBeR) project's Integrating Climate and Ecosystem Dynamics in the Southern Ocean (ICED) program. This paper contributes to the British Antarctic Survey (BAS) Polar Science for Planet Earth "Ecosystems" and "Biodiversity, Evolution \& Adaptation" programs, the BAS Environment Office Long Term Monitoring and Survey project (EO-LTMS), and the SCAR Integrated Science to Inform Antarctic and Southern Ocean Conservation (Ant-ICON) program. We thank the MEASO Support Group and Steering Committee for assisting with figures, coordination, and editing of the text. We thank Stacey McCormack from Visual Knowledge for developing the infographic for Figure $\mathbf{1 .}$ We also thank the stakeholders who provided feedback for this manuscript during the MEASO consultation process, including: ACAP, ARK, the Pew Charitable Trusts, SOOS, and WWF. We are grateful to the two reviewers for their constructive comments and suggestions to improve the manuscript. 


\section{REFERENCES}

Abrams, P. A., Ainley, D. G., Blight, L. K., Dayton, P. K., Eastman, J. T., and Jacquet, J. L. (2016). Necessary elements of precautionary management: implications for the Antarctic toothfish. Fish Fish 17, 1152-1174. doi: 10.1111/faf.12162

Absher, T. M., Ferreira, S. L., Kern, Y., Ferreira, A. L., Christo, S. W., and Ando, R. A. (2019). Incidence and identification of microfibers in ocean waters in Admiralty Bay, Antarctica. Environ. Sci. Pollut. Res. 26, 292-298. doi: 10.1007/ s11356-018-3509-6

Acevedo-Gutierrez, A., Croll, D. A., and Tershy, B. R. (2002). High feeding costs limit dive time in the largest whales. J. Exp. Biol. 205, 1747-1753. doi: 10.1242/ jeb.205.12.1747

Amelung, B., and Lamers, M. (2007). Estimating the greenhouse gas emissions from Antarctic tourism. Tour. Mar. Environ. 4, 121-133. doi: 10.3727/ 154427307784772020

Arnould, J. P. Y., and Croxall, J. P. (1995). Trends in entanglement of Antarctic fur seals (Arctocephalus gazella) in man-made debris at South Georgia. Mar. Pollut. Bull. 30, 707-712. doi: 10.1016/0025-326x(95)00054-q

Aronson, R. B., Thatje, S., McClintock, J. B., and Hughes, K. A. (2011). Anthropogenic impacts on marine ecosystems in Antarctica. Ann. N. Y. Acad. Sci. 1223, 82-103. doi: 10.1111/j.1749-6632.2010.05926.x

Arrigo, K. R., van Dijken, G., and Pabi, S. (2008). Impact of a shrinking Arctic ice cover on marine primary production. Geophys. Res. Lett. 35:L19603. doi: 10.1029/2008GL035028

Ashton, G. V., Morley, S. A., Barnes, D. K. A., Clark, M. S., and Peck, L. S. (2017). Warming by $1{ }^{\circ} \mathrm{C}$ drives species and assemblage level responses in antarctica's marine shallows. Curr. Biol. 27, 2698-2705. doi: 10.1016/j.cub.2017.07.048

ATCM (2009). "Report of the joint CEP/SC-CAMLR workshop," Paper Presented at the 55th Russian Federation and the United States, Submitted by Delegations of France, New Zealand, Virginia.

Avila, C., Angulo-Preckler, C., Martín-Martín, R. P., et al. (2020). Invasive marine species discovered on non-native kelp rafts in the warmest Antarctic island. Sci. Rep. 10:1639. doi: 10.1038/s41598-020-58561-y

Barnes, D. K. A. (2017). Iceberg killing fields limit huge potential for benthic blue carbon in Antarctic shallows. Glob. Change Biol. 23, 2649-2659. doi: 10.1111/ gcb. 13523

Barnes, D. K. A., and Fraser, K. P. (2003). Rafting by five phyla on man-made flotsam in the Southern Ocean. Mar. Ecol. Prog. Ser. 262, 289-291. doi: 10. 3354/meps262289

Barnes, D. K. A., and Souster, T. (2011). Reduced survival of Antarctic benthos linked to climate-induced iceberg scouring. Nat. Clim. Change 1, 365-368. doi: $10.1038 /$ nclimate 1232

Barnes, D. K. A., Fleming, A., Sands, C. J., Quartino, M. L., and Deregibus, D. (2018). Icebergs, sea ice, blue carbon and Antarctic climate feedbacks. Phil. Trans. R. Soc. A 376:37620170176. doi: 10.1098/rsta.2017.0176

Barnes, D. K. A., Hodgson, D. A., Convey, P., Allen, C. S., and Clarke, A. (2006). Incursion and excursion of Antarctic biota: past, present and future. Glob. Ecol. Biogeogr. 15, 121-142. doi: 10.1111/j.1466-822x.2006.00216.x

Barnes, D. K. A., Kaiser, S., Griffiths, H. J., and Linse, K. (2009). Marine, intertidal, freshwater and terrestrial biodiversity of an isolated polar archipelago. J. Biogeogr. 36, 756-769. doi: 10.1111/j.1365-2699.2008.02030.x

Barnes, D. K. A., Walters, A., and Gonçalves, L. (2010). Macroplastics at sea around Antarctica. Mar. Environ. Res. 70, 250-252. doi: 10.1016/j.marenvres.2010.05. 006

Bender, N. A., Crosbie, K., and Lynch, H. J. (2016). Patterns of tourism in the Antarctic Peninsula region: a 20-year analysis. Ant. Sci. 28, 194-203. doi: 10.1017/s0954102016000031

Benson, A., Brooks, C. M., Canonico, G., Duffy, E., Muller-Karger, F., Sosik, H. M., et al. (2018). Integrated observations and informatics improve understanding of changing marine ecosystems. Front. Mar. Sci. 5:428. doi: 10.3389/fmars.2018. 00428

Bessa, F., Ratcliffe, N., Otero, V., Sobral, P., Marques, J. C., Waluda, C. M., et al. (2019). Microplastics in gentoo penguins from the Antarctic region. Sci. Reps. 9:14191.

Bestley, S., Ropert-Coudert, Y., Bengtson Nash, S., Brooks, C. M., Cotté, C., Dewar, M., et al. (2020). Marine ecosystem assessment for the southern ocean: birds and marine mammals in a changing climate. Front. Ecol. Evol. 8:566936. doi: $10.3389 /$ fevo. 2020.566936
Bonner, W. N., and McCann, T. S. (1982). Neck collars on fur seals Arctocephalus gazella, at South Georgia. Br. Antarct. Surv. Bull. 57, 73-77.

Branch, T. A. (2007). Abundance of Antarctic blue whales south of $60^{\circ} \mathrm{S}$ from three complete circumpolar sets of surveys. J. Cetacean Res. Manage. 9, 253-262.

Branch, T. A. (2011). Humpback abundance south of $60^{\circ} \mathrm{S}$ from three complete circumpolar sets of surveys. J. Cetacean Res. Manage. 3, 53-70. doi: 10.47536/ jcrm.vi.305

Branch, T. A., Matsuoka, K., and Miyashita, T. (2004). Evidence for increases in Antarctic blue whales based on Bayesian modelling. Mar. Mamm. Sci. 20, 726-754. doi: 10.1111/j.1748-7692.2004.tb01190.x

Branch, T. A., Stafford, K. M., Palacios, D. M., Allison, C., et al. (2007). Past and present distribution, densities and movements of blue whales Balaenoptera musculus in the Southern Hemisphere and northern Indian Ocean. Mamm. Rev. 37, 116-175. doi: 10.1111/j.1365-2907.2007.00106.x

Brasier, M. J., Barnes, D., Bax, N., Brandt, A., Christianson, A., Constable, A. J., et al. (2021). Responses of Southern Ocean seafloor habitats and communities to global environmental changes. Front. Ecol. Evol. 8:622721. doi: 10.3389/fmars. 2021.622721

Brooks, C. M., Chown, S. L., Douglass, L. L., Raymond, B. P., Shaw, J. D., Sylvester, Z. T., et al. (2020). Progress towards a representative network of Southern Ocean protected areas. PLoS One 15:e0231361. doi: 10.1371/journal. pone. 0231361

Brooks, C. M., Epstein, G., and Ban, N. C. (2019). Managing marine protected areas in remote areas: the case of the subantarctic Heard and McDonald Islands. Front. Mar. Sci. 6:631. doi: 10.3389/fmars.2019.00631

Brooks, S. T., Jabour, J., van den Hoff, J., and Bergstrom, D. M. (2019). Our footprint on Antarctica competes with nature for rare ice-free land. Nat. Sustainab. 2, 185-190. doi: 10.1038/s41893-019-0237-y

Burger, J., and Gochfeld, M. (2007). Responses of Emperor Penguins (Aptenodytes forsteri) to encounters with ecotourists while commuting to and from their breeding colony. Polar Biol. 30, 1303-1313. doi: 10.1007/s00300-0070291-1

Caccavo, J. A., Brooks, C., Constable, A., Christiansen, H., Cotte, C., Desvignes, T., et al. (in press). Productivity and change in fish and squid in the Southern Ocean. Front. Ecol. Evol.

Calderan1, S. V., Black, A., Branch, T. A., Collins, M. A., Kelly, N., Leaper, R., et al. (2020). South Georgia blue whales five decades after the end of whaling. Endang. Species Res. 43, 359-373. doi: 10.3354/esr01077

Candy, S. G., and Constable, A. J. (2008). An integrated stock assessment for the Patagonian toothfish (Dissostichus eleginoides) for the Heard and McDonald Islands using CASAL. CCAMLR Sci. 15, 1-34.

Cárdenas, L., Leclerc, J., Bruning, P., Garrido, I., et al. (2020). First mussel settlement observed in Antarctica reveals the potential for future invasions. Sci. Rep. 10:5552.

Carroll, E. L., Childerhouse, S. J., Fewster, R. M., Patenaude, N. J., et al. (2013). Accounting for female reproductive cycles in a superpopulation capturerecapture framework: application to southern right whales. Ecol. Appl. 23, 1677-1690. doi: 10.1890/12-1657.1

Cavan, E. L., Belcher, A., Atkinson, A., Hill, S. L., Kawaguchi, S., McCormack, S., et al. (2019). The importance of Antarctic krill in biogeochemical cycles. Nat. Commun. 10:4742.

Cavanagh, R. D., Melbourne-Thomas, J., Grant, S. M., Barnes, D. K. A., Hughes, K. A., Halfter, D., et al. (2021). Future risks for Southern Ocean ecosystem services under climate change. Front. Ecol. Evol. 7:615214. doi: 10.3389/fmars. 2020.615214

CCAMLR (2007). Report of the Twenty-Sixth Meeting of the Commission for the Conservation of Antarctic Marine Living Resources. Hobart: CCAMLR Secretariat.

CCAMLR (2008). Report of the Twenty-Seventh Meeting of the Commission for the Conservation of Antarctic Marine Living Resources. Hobart: CCAMLR Secretariat.

CCAMLR (2016). Conveners report of the joint CEP/SC-CAMLR workshop on climate change and monitoring. Paper Presented at the SC-CAMLR-XXXV, 17-21 October 2016, Hobart, TAS.

CCAMLR (2017). Second Performance Review of CCAMLR - Final Report of the Panel. CCAMLR-XXVI/01. Hobart: CCAMLR.

CCAMLR (2019). CCAMLR Statistical Bulletin, Vol. 31. Hobart: CCAMLR Secretariat. 
Chile (2008). "Background to the pollution incident caused by the sinking of the MS explorer," Paper Presented at the Antarctic Treaty Consultative Meeting XXXI, Kyiv, 2-13. doi: 10.1016/0025-326x(70)90346-2

Chown, S. L., Huiskes, A. H. L., Gremmen, N. J. M., Lee, J. E., Terauds, A., Crosbie, K., et al. (2012). Continent-wide risk assessment for the establishment of nonindigenous species in Antarctica. PNAS 109, 4938-4943. doi: 10.1073/ pnas. 1119787109

Clarke, A., and Harris, C. M. (2003). Polar marine ecosystems: major threats and future change. Environ. Conserv. 30, 1-25. doi: 10.1017/s0376892903000018

Clarke, A., Barnes, D. K. A., and Hodgson, D. A. (2005). How isolated is Antarctica? Trends Ecol. Evol. 20, 1-3. doi: 10.1016/j.tree.2004.10.004

Clay, T. A., Small, C., Tuck, G. N., Pardo, D., Carneiro, A. P. B., Wood, A. G., et al. (2019). A comprehensive large-scale assessment of fisheries bycatch risk to threatened seabird populations. J. Appl. Ecol. 56, 1882-1893. doi: 10.1111/ 1365-2664.13407

Clayton, M., Wiencke, C., and Klöser, H. (1997). New records of temperate and sub-Antarctic marine benthic macroalgae from Antarctica. Polar Biol. 17, 141-149. doi: 10.1007/s003000050116

COMNAP (2017). Antarctic Station Catalogue. Council of Managers of National Antarctic Programs. Christchurch: COMNAP.

Conlan, K. E., Kim, S. L., Lenihan, H. S., and Oliver, J. S. (2004). Benthic changes during 10 years of organic enrichment by McMurdo Station, Antarctica. Mar. Poll. Bull. 49, 43-60. doi: 10.1016/j.marpolbul.2004.01.007

Constable, A. J. (2002). CCAMLR ecosystem monitoring and management: future work. CCAMLR Sci. 9, 233-253.

Constable, A. J. (2011). Lessons from CCAMLR on the implementation of the ecosystem approach to managing fisheries. Fish Fish. 12, 138-151. doi: 10.1111/ j.1467-2979.2011.00410.x

Constable, A. J., and Welsford, D. C. (2011). "Developing a precautionary, ecosystem approach to managing fisheries and other marine activities at heard island and mcdonald islands in the Indian Sector of the Southern Ocean," in The Kerguelen Plateau: Marine Ecosystem and Fisheries, eds G. Duhamel and D. C. Welsford (Paris: Société Française d'Ichtyologie), 233-255.

Constable, A. J., Costa, D. P., Schofield, O., Newman, L., Urban, E. R. Jr., Fulton, E. A., et al. (2016a). Developing priority variables ("ecosystem essential ocean variables" - eEOVs) for observing dynamics and change in Southern Ocean ecosystems. J. Mar. Syst. 161, 26-41. doi: 10.1016/j.jmarsys.2016. 05.003

Constable, A. J., de la Mare, W. K., Agnew, D. J., Everson, I., and Miller, D. (2000). Managing fisheries to conserve the Antarctic marine ecosystem: practical implementation of the Convention on the Conservation of Antarctic Marine Living Resources (CCAMLR). ICES J. Mar. Sci. 57, 778-791. doi: 10.1006/jmsc. 2000.0725

Constable, A. J., Kawaguchi, S., and Sumner, M. (2016b). A Method for Spreading the Risk of Localised Effects of Catches of Antarctic Krill up to the Trigger Level, During the Development of Stage 2 of Feedback Management. WG-EMM-16/69. Hobart: CCAMLR.

Constable, A. J., Melbourne-Thomas, J., Trebilco, R., Press, A. J., and Haward, M. (2017). ACE CRC Position Analysis: Managing Change in Southern Ocean Ecosystems. Hobart: Antarctic Climate and Ecosystems Cooperative Research Centre.

Constable, A. J., Meredith, M. P., Ducklow, H. W., Murphy, E. J., Linse, K., and Kawaguchi, S. (2016c). "Impacts and effects of ocean warming on Antarctic ecosystems and species," in Explaining Ocean Warming: Causes, Scale, Effects and Consequences, eds D. Laffoley and J. M. Baxter (Gland: IUCN), 337-355.

Convey, P., Barnes, D. K. A., and Morton, A. (2002). Debris accumulation on oceanic island shores of the Scotia Arc, Antarctica. Polar Biol. 25, 612-617. doi: $10.1007 / \mathrm{s} 00300-002-0391-x$

Cooke, J., Rowntree, V., and Payne, R. (2001). Estimates of demographic parameters for southern right whales (Eubalaena australis) observed off Peninsula Valdes, Argentina. J. Cetacean Res. Manage. 2, 125-132. doi: 10. 47536/jcrm.vi.297

Cox, M. J., Demer, D. A., Warren, J. D., Cutter, G. R., and Brierley, A. S. (2009). Multibeam echosounder observations reveal interactions between Antarctic krill and air-breathing predators. Mar. Ecol. Prog. Ser. 378, 199-209. doi: 10.3354/meps07795
Crockett, A. B., and White, G. J. (2003). Mapping sediment contamination and toxicity in Winter Quarters Bay, McMurdo Station, Antarctica. Environ. Monit. Assess. 85, 257-275.

Croxall, J. P. (2008). The role of science and advocacy in the conservation of Southern Ocean albatrosses at sea. Bird Conserv. Int. 18, S13-S29.

Croxall, J. P., and Nicol, S. (2004). Management of Southern Ocean fisheries: global forces and future sustainability. Ant. Sci. 16, 569-584. doi: 10.1017/ s0954102004002330

Cunningham, E. M., Ehleer, S. M., Dick, J. T. A., Sigwart, J. D., Linse, K., Dick, J. J., et al. (2020). High abundances of microplastic pollution in deep-sea sediments evidence from Antarctica and the Southern Ocean. Env. Sci. Technol. 54, 13661-13671. doi: 10.1021/acs.est.0c03441

Deregibus, D., Quartino, M. L., Zacher, K., Campana, G. L., and Barnes, D. K. A. (2017). Understanding the link between sea ice, ice scour and Antarctic benthic biodiversity; the need for cross station and nation collaboration. Polar Rec. 53, 143-152. doi: 10.1017/S0032247416000875

Duarte, C. M., Agusti, S., Barbler, E., Britten, G. L., Castilla, J. C., Gattuso, J.-P., et al. (2020). Rebuilding marine life. Nature 580, 39-51.

Ducklow, H. W., Fraser, W. R., Meredith, M. P., Stammerjohn, S. E., Doney, S. C., Martinson, D. G., et al. (2013). West Antarctic Peninsula: an ice-dependent coastal marine ecosystem in transition. Oceanography 26, 190-203. doi: 10. 5670/oceanog.2013.62

Dunn, M. J., Forcada, J., Jackson, J. A., Waluda, C. M., Nichol, C., and Trathan, P. N. (2019). A long-term study of gentoo penguin (Pygoscelis papua) population trends at a major Antarctic tourist site, Goudier Island, Port Lockroy. Biodivers. Conserv. 28, 37-53. doi: 10.1007/s10531-018-1635-6

Eijgelaar, E., Thaper, C., and Peeters, P. (2010). 'Antarctic cruise tourism: the paradoxes of ambassadorship, "last chance tourism" and greenhouse gas emissions'. J. Sustain. Tour. 18, 337-354. doi: 10.1080/09669581003653534

Emnet, P., Gaw, S., Northcott, G., Storey, B., and Graham, L. (2015). Personal care products and steroid hormones in the Antarctic coastal environment associated with two Antarctic research stations, McMurdo Station and Scott Base. Environm. Res. 136, 331-342. doi: 10.1016/j.envres.2014.10.019

Eppley, Z. A., and Rubega, M. A. (1990). Indirect effects of an oil spill: reproductive failure in a population of South Polar skuas following the 'Bahia Paraiso' oil spill in Antarctica. Mar. Ecol. Prog. Ser. 67, 1-6. doi: 10.3354/meps 067001

Eriksson, C., and Burton, H. (2003). Origins and biological accumulation of small plastic particles in fur-seal scats from Macquarie Island. Ambio 32, 380-384. doi: 10.1579/0044-7447-32.6.380

Foley, C. M., and Lynch, H. J. (2020). A method to estimate pre-exploitation population size. Conserv. Biol. 34, 256-265. doi: 10.1111/cobi.13416

Fraser, C. I., Morrison, A. K., Hogg, A. M., Macaya, E. C., van Sebille, E., Ryan, P. G., et al. (2018). Antarctica's ecological isolation will be broken by storm-driven dispersal and warming. Nat. Clim. Change 8, 704-708. doi: 10.1038/s41558018-0209-7

Frenot, Y., Chown, S. L., Whinam, J., Selkirk, P., Convey, P., Skotnicki, M., et al. (2005). Biological invasions in the Antarctic: extent, impacts and implications. Biol. Rev. 80, 45-72. doi: 10.1017/s1464793104006542

Friedlaender, A. S., Goldbogen, J. A., Hazen, E. L., Calambokidis, J., and Southall, B. L. (2015). Feeding performance by sympatric blue and fin whales exploiting a common prey resource. Mar. Mamm. Sci. 31, 345-354. doi: 10.1111/mms. 12134

Friedlaender, A. S., Goldbogen, J. A., Nowacek, D. P., Read, A. J., Johnston, D., and Gales, N. (2014). Feeding rates and under-ice foraging strategies of the smallest lunge filter feeder, the Antarctic minke whale (Balaenoptera bonaerensis). J. Exp. Biol. 217, 2851-2854. doi: 10.1242/jeb.106682

Friedlaender, A. S., Johnston, D. W., Tyson, R. B., Kaltenberg, A., et al. (2016). Multiple-stage decisions in a marine central-place forager. R. Soc. Open Sci. 3:160043. doi: $10.1098 /$ rsos. 160043

Friedlaender, A. S., Lawson, G. L., and Halpin, P. N. (2009). Evidence of resource partitioning between humpback and minke whales around the western Antarctic Peninsula. Mar. Mamm. Sci. 25, 402-415. doi: 10.1111/j.1748-7692. 2008.00263.x

Goldbogen, J. A., Calambokidis, J., Oleson, E., Potvin, J., Pyenson, N. D., Schorr, G., et al. (2011). Mechanics, hydrodynamics and energetics of blue whale lunge feeding: efficiency dependence on krill density. J. Exp. Biol. 214, 131-146. doi: $10.1242 / \mathrm{jeb} .048157$ 
Grant, S. M., Hill, S. L., Murphy, E. J., and Trathan, P. N. (2013). Ecosystem services of the Southern Ocean: trade-offs in decision-making. Antarct. Sci. 25, 603-617. doi: $10.1017 /$ s0954102013000308

Gregory, M. R., and Ryan, P. G. (1997). "Pelagic plastics and other seaborne persistent synthetic debris: a review of Southern Hemisphere perspectives," in Marine Debris-Sources, Impacts and Solutions, eds J. M. Coe and D. B. Rogers (New York, NY: Springer-Verlag), 49-66. doi: 10.1007/978-1-4613-8486-1_6

Gregory, M. R., Kirk, R. M., and Mabin, M. C. G. (1984). Pelagic tar, oil, plastics and other litter in surface waters of the New Zealand sector of the Southern Ocean, and on Ross Dependency shores. N. Z. Antarct. Rec. 6, 12-28.

Griffiths, H. J., Whittle, R. J., Roberts, S. J., Belchier, M., and Linse, K. (2013). Antarctic crabs: invasion or endurance? PLoS One 8:e66981. doi: 10.1371/ journal.pone.0066981

Gröndahl, F., Siedenmark, J., and Thomsen, A. (2008). Survey of wastewater disposal practices at Antarctic research stations. Polar Res. 28, 298-306. doi: 10.1111/j.1751-8369.2008.00056.x

Gutt, J. (2001). On the direct impact of ice on marine benthic communities, a review. Polar Biol. 24, 553-564. doi: 10.1007/s003000100262

Hale, R. C., Kim, S. L., Harvey, E., La Guardia, M. J., Mainor, T. M., Bush, E. O., et al. (2008). Antarctic research bases: local sources of polybrominated diphenyl ether (PBDE) flame retardants. Environ. Sci. Technol. 42, 1452-1457. doi: 10.1021/es702547a

Halpern, B. S., Walbridge, S., Selkoe, K. A., Kappel, C. V., Micheli, F., D’Agrosa, C., et al. (2008). A global map of human impact on marine ecosystems. Science $5865,948-952$.

Henley, S. F., Cavan, E. L., Fawcett, S. E., Kerr, R., Monteiro, T., Sherrell, R. M., et al. (2020). Changing biogeochemistry of the Southern Ocean and its ecosystem implications. Front. Mar. Sci. 7:581. doi: 10.3389/fmars.2020. 00581

Hill, S. L., Atkinson, A., Darby, C., Fielding, S., Krafft, B. A., Godo, O. R., et al. (2016). Is current management of the Antarctic krill fishery in the Atlantic sector of the Southern Ocean precautionary? CCAMLR Sci. 23, 31-51.

Hill, S. L., Murphy, E. J., Reid, K., Trathan, P. N., and Constable, A. J. (2006). Modelling Southern Ocean ecosystems: krill, the food-web, and the impacts of harvesting. Biol. Rev. 81, 581-608. doi: 10.1017/S146479310600 7123

Hillary, R., Kirkwood, G. P., and Agnew, D. (2006). An assessment of toothfish in subarea 48.3 using CASAL. CCAMLR Sci. 13, 65-95.

Hoffman, J. I., Grant, S. M., Forcada, J., and Phillips, C. D. (2011). Bayesian inference of a historical bottleneck in a heavily exploited marine mammal. $\mathrm{Mol}$. Ecol. 20, 3989-4008. doi: 10.1111/j.1365-294x.2011.05248.x

Horton, A. A., and Barnes, D. K. A. (2020). Microplastic pollution in a rapidly changing world: implications for remote and vulnerable marine ecosystems. Sci. Total Environ. 738:140349. doi: 10.1016/j.scitotenv.2020.140349

Hughes, K. A. (2003). The influence of seasonal environmental variables on the distribution of presumptive fecal coliforms around an Antarctic research station. Appl. Environ. Microbiol. 69, 4884-4891. doi: 10.1128/AEM.69.8.48844891.2003

Hughes, K. A. (2004). Reducing sewage pollution in the Antarctic marine environment using a sewage treatment plant. Mar. Pollut. Bull. 49, 850-853. doi: 10.1016/j.marpolbul.2004.05.012

Hughes, K. A., and Convey, P. (2020). Implications of the COVID-19 pandemic for Antarctica. Antarct. Sci. 32, 426-439. doi: 10.1017/S095410202000053X

Hughes, K. A., and Nobbs, S. J. (2004). Long-term survival of human faecal microorganisms on the Antarctic Peninsula. Antarct. Sci. 16, 293-297. doi: $10.1017 /$ S095410200400210X

Hughes, K. A., and Thompson, A. (2004). Distribution of sewage pollution around a maritime Antarctic research station indicated by faecal coliforms, Clostridium perfringens and faecal sterol markers. Environ. Pollut. 127, 315-321. doi: 10. 1016/j.envpol.2003.09.004

Hughes, K. A., Constable, A., Frenot, Y., López-Martínez, J., McIvor, E., Njåstad, B., et al. (2018). Antarctic environmental protection: strengthening the links between science and governance. Environ. Sci. Policy 83, 86-95.1.

Hughes, K. A., Pescott, O. L., Peyton, J., et al. (2020). Invasive non-native species likely to threaten biodiversity and ecosystems in the Antarctic Peninsula region. Glob. Change Biol. 26, 2702-2716. doi: 10.1111/gcb.14938
Hughes, K. A., Waluda, C. M., Stone, R. E., et al. (2008). Short-term responses of king penguins Aptenodytes patagonicus to helicopter disturbance at South Georgia. Polar Biol. 31, 1521-1530. doi: 10.1007/s00300-008-0492-2

Huin, N., and Croxall, J. P. (1996). Fishing gear, oil and marine debris associated with seabirds at Bird Island, South Georgia, during 1993/1994. Mar. Ornithol. 24, 19-22.

IAATO (2018). "IAATO overview of Antarctic tourism: 2017-18 season and preliminary estimates for 2018-19 season," in Information Paper 071 Presented at the Antarctic Treaty Consultative Meeting XLI, (Buenos Aires). Available online at: https://iaato.org/wp-content/uploads/2020/03/IAATO-overview.pdf (accessed September 7, 2020).

IAATO (2019). "IAATO overview of Antarctic tourism: 2018-19 season and preliminary estimates for 2019-20 season," in Information Paper 040 Presented at the Antarctic Treaty Consultative Meeting XLII (Prague). Available online at: https://iaato.org/wp-content/uploads/2020/03/IP140-IAATO-Overviewof-Antarctic-Tourism-2018-19-Season-and-Preliminary-Estimates-for-201920-Season.pdf (accessed September 7, 2020).

Isobe, A., Uchiyama-Matsumoto, K., Uchida, K., and Tokai, T. (2017). Microplastics in the Southern Ocean. Mar. Pollut. Bull. 114, 623-626. doi: 10.1016/j.marpolbul.2016.09.037

IWC (2013). Annex G: report of the sub-committee on in-depth assessments. J. Cetacean Res. Manage. 14, 195-213.

IWC (2016). Annex H: report of the sub-committee on other southern hemisphere whale stocks. J. Cetcean Res. Manage. 17, 250-282.

Jackson, J. A., Kennedy, A. S., Moore, M., Andriolo, A., Bamford, C., Calderan, S., et al. (2020). Whales return to a historical hotspot of industrial whaling? The pattern of southern right whale (Eubalaena australis) recovery at South Georgia. Endang. Spec. Res. 43, 323-339.

Jackson, J. A., Ross-Gillespie, A., Butterworth, D., Findlay, K., et al. (2015). Southern Hemisphere Humpback Whale Comprehensive Assessment - A Synthesis and Summary: 2005-2015 Paper SC/66a/SH3 Presented to the IWC Scientific Committee. Available online at: www.iwc.int (accessed September 18, 2020).

Johnston, D. W., Friedlaender, A. S., Read, A. J., and Nowacek, D. P. (2012). Initial density estimates of humpback whales Megaptera novaeangliae in the inshore waters of the western Antarctic Peninsula during the late autumn. Endang. Species Res. 18, 63-71. doi: 10.3354/esr00395

Jones-Williams, K., Galloway, T. S., Cole, M., Stowasser, G., Waluda, C. M., and Manno, C. (2020). Close encounters - microplastic availability to pelagic amphipods in sub-Antarctic and Antarctic surface waters. Environ. Int. 140:105792. doi: 10.1016/j.envint.2020.105792

Kawaguchi, S., and Nicol, S. (2020). "Krill fishery," in Fisheries and Aquaculture, eds G. Lovrich and M. Thiel (Oxford: Oxford University Press), 137-158. doi: 10.1093/oso/9780190865627.003.0006

Kawaguchi, S., Nicol, S., and Press, A. J. (2009). Direct effects of climate change on the Antarctic krill fishery. Fish. Manag. Ecol. 16, 424-427. doi: 10.1111/j.13652400.2009.00686.x

Kennicutt, M. C. (1990). Oil spillage in Antarctica. Environ. Sci. Technol. 24, 620-624.

Kennicutt, M. C., Sweet, S. T., Fraser, W. R., Stockton, W. L., and Culver, M. (1991). Grounding of the Bahía Paraíso at Arthur Harbor, Antarctica: I. distribution and fate of oil spill related hydrocarbons. Environ. Sci. Technol. 25, 509-518. doi: 10.1021/es00015a020

King, J. (1959). The northern and southern populations of Arctocephalus gazella. Mammalia 23, 19-40.

Klein, E. S., Hill, S. L., Hinke, J. T., Phillips, T., and Watters, G. M. (2018). Impacts of rising sea temperature on krill increase risks for predators in the Scotia Sea. PLoS One 13:e0191011. doi: 10.1371/journal.pone.0191011

Kock, K., Reid, K., Croxall, J., and Nicol, S. (2007). Fisheries in the Southern Ocean: an ecosystem approach. Philos. Trans. R. Soc. B Biol. Sci. 362, 2333-2349.

Kock, K.-H. (1992). Antarctic Fish and Fisheries. Cambridge: Cambridge University Press.

Koubbi, P., Grant, S., Ramm, D., Vacchi, M., Ghigliotti, L., and Pisano, E. (2017). "Impact of climate change on the antarctic silverfish and its consequences for the Antarctic ecosystem," in The Antarctic Silverfish: A Keystone Species in a Changing Ecosystem, eds M. Vacchi, E. Pisano, and L. Ghigliotti (Berlin: Springer), 287-305. 
Lacerda, A. L., Rodrigues, L., van Sebille, E., Rodrigues, F. L., Ribero, L., Secchi, E. R., et al. (2019). Plastics in sea surface waters around the Antarctic Peninsula. Sci. Rep. 9:3977.

Larsen, J. N., Anisimov, O. A., Constable, A., Hollowed, A. B., Maynard, N., Prestrud, P., et al. (2014). "Polar regions," in Climate Change 2014: Impacts, Adaptation, and Vulnerability. Part B: Regional Aspects. Contribution of Working Group II to the Fifth Assessment Report of the Intergovernmental Panel on Climate Change, eds V. R. Barros, C. B. Field, D. J. Dokken, M. D. Mastrandrea, K. J. Mach, and T. E. Bilire (Cambridge: Cambridge University Press), 1567-1612.

Lavery, T. J., Roudnew, B., Seymour, J., Mitchell, J. G., Smetacek, V., and Nicol, S. (2014). Whales sustain fisheries: blue whales stimulate primary production in the Southern Ocean. Mar. Mamm. Sci. 30, 888-904. doi: 10.1111/mms.12108

Le Guen, C., Suaria, G., Sherley, R. B., Ryan, P. G., Aliani, S., Boehme, L., et al. (2020). Microplastic study reveals the presence of natural and synthetic fibres in the diet of King Penguins (Aptenodytes patagonicus) foraging from South Georgia. Environ. Int. 134:105303. doi: 10.1016/j.envint.2019.105303

Lee, J. E., and Chown, S. L. (2007). Mytilus on the move: transport of an invasive bivalve to the Antarctic. Mar. Ecol. Prog. Ser. 339, 307-310. doi: 10.3354/meps3 39307

Lee, J. R., Raymond, B., Bracegirdle, T. J., Chades, I., Fuller, R. A., Shaw, J. D., et al. (2017). Climate change drives expansion of Antarctic ice-free habitat. Nature 547, 49-54. doi: 10.1038/nature22996

Leeming, R., Stark, J. S., and Smith, J. J. (2015). Novel use of faecal sterols to assess human faecal contamination in Antarctica: a likelihood assessment matrix for environmental monitoring. Antarct. Sci. 27, 31-43. doi: 10.1017/ S0954102014000273

Lenihan, H., and Oliver, J. (1995). Anthropogenic and natural disturbances to marine benthic communities in Antarctica. Ecol. Appl. 5, 311-326. doi: 10.2307/ 1942024

Lewis, P. N., Hewitt, C. L., Riddle, M., and McMinn, A. (2003). Marine introductions in the Southern Ocean: an unrecognised hazard to biodiversity. Mar. Pollut. Bull. 46, 213-223. doi: 10.1016/s0025-326x(02)00364-8

Liggett, D., McIntosh, A., Thompson, A., Gilbert, N., and Storey, B. (2011). From frozen continent to tourism hotspot? Five decades of Antarctic tourism development and management and a glimpse into the future. Tour. Manag. 32, 357-366. doi: 10.1016/j.tourman.2010.03.005

Ling, J. K. (1999). Exploitation of fur seals and sea lions from Australian, New Zealand and adjacent subantarctic islands during the eighteenth, nineteenth and twentieth centuries. Austral. Zool. 31, 323-350. doi: 10.7882/ az.1999.036

Mastrandrea, M. D., Mach, K. J., Plattner, G.-K., Edenhofer, O., Stocker, T. F., Field, C. B., et al. (2011). The IPCC AR5 guidance note on consistent treatment of uncertainties: a common approach across the working groups. Clim. Change 108, 675-691. doi: 10.1007/s10584-011-0178-6

McCarthy, A. H., Peck, L. S., Hughes, K. A., and Aldridge, D. C. (2019). Antarctica: the final frontier for marine biological invasions. Glob. Change Biol. 25, $2221-$ 2241. doi: $10.1111 / \mathrm{gcb} .14600$

McCormack, S. A., Melbourne-Thomas, J., Trebilco, R., Blanchard, J. L., and Constable, A. (2019). Alternative energy pathways in Southern Ocean food webs: insights from a balanced model of Prydz Bay, Antarctica. Deep Sea Res. Part II Top. Stud. Oceanogr. 174:104613. doi: 10.1016/j.dsr2.2019.07.001

Meyer, B., Atkinson, A., Bernard, K. S., et al. (2020). Successful ecosystem-based management of Antarctic krill should address uncertainties in krill recruitment, behaviour and ecological adaptation. Commun. Earth Environ. 1:28. doi: 10. 1038/s43247-020-00026-1

Michael, P. E., Thomson, R., Barbraud, C., Delord, K., et al. (2017). Illegal fishing bycatch overshadows climate as a driver of albatross population decline. Mar. Ecol. Prog. Ser. 579, 185-199. doi: 10.3354/meps12248

Millennium Ecosystem Assessment (2005). Ecosystems and Human Wellbeing: Current States and Trends. Washington DC: Island Press, 948.

Miller, E. J., Potts, J. M., Cox, M. J., Miller, B. S., et al. (2019). The characteristics of krill swarms in relation to aggregating Antarctic blue whales. Sci. Rep. 9:16487.

Monteiro, R. C. P., Ivar, do Sul, J. A., and Costa, M. F. (2018). Plastic pollution in islands of the Atlantic Ocean. Environ. Pollut. 238, 103-110.

Moore, M. J., Berrow, S. D., Jensen, B. A., Carr, P., Sears, R., Rowntree, V. J., et al. (1999). Relative abundance of large whales around South Georgia (1979-1998). Mar. Mamm. Sci. 15, 1287-1302. doi: 10.1111/j.1748-7692.1999.tb00891.x
Morley, S. A., Abele, D., Barnes, D., Cárdenas, C., Cotté, C., Gutt, J., et al. (2020). Global drivers on Southern Ocean ecosystems: changing physical environments and anthropogenic pressures in an Earth System. Front. Mar. Sci. 7:547188. doi: $10.3389 /$ fmars. 2020.547188

Morley, S. A., Barnes, D. K. A., and Dunn, M. J. (2019). Predicting which species succeed in climate-forced polar seas. Front. Mar. Sci. 5:507. doi: 10.3389/fmars. 2018.00507

Mormede, S., Dunn, A., and Hanchet, S. (2014). A stock assessment model of Antarctic toothfish (Dissostichus mawsoni) in the Ross Sea Region incorporating multi-year mark-recapture data. CCAMLR Sci. 21, 39-62.

Munari, C., Infantini, V., Scoponi, M., Rastelli, E., Corinaldesi, C., and Mistri, M. (2017). Microplastics in the sediments of Terra Nova Bay (Ross Sea. Antarctica). Mar. Pollut. Bull. 122, 161-165. doi: 10.1016/j.marpolbul.2017.06.039

Nel, D. C., and Nel, J. L. (1999). Marine debris and fishing gear associated with seabirds at sub-Antarctic Marion Island 1996/97 and 1997/98: in relation to longline fishing activity. CCAMLR Sci. 6, 85-96.

Newman, L., Heil, P., Trebilco, R., Katsumata, K., Constable, A., et al. (2019). Delivering sustained, coordinated, and integrated observations of the Southern Ocean for global impact. Front. Mar. Sci. 6:433. doi: 10.3389/fmars.2019. 00433

Nicol, S., and Foster, J. (2016). "The fishery for antarctic krill: its current status and management regime," in Biology and Ecology of Antarctic Krill, ed. V. Siegel (Cham: Springer International Publishing), 387-421. doi: 10.1007/978-3-31929279-3_11

Nicol, S., Croxall, J., Trathan, P., Gales, N., and Murphy, E. (2007). Paradigm misplaced? Antarctic marine ecosystems are affected by climate change as well as biological processes and harvesting. Antarct. Sci. 19, 291-295. doi: 10.1017/ s0954102007000491

Noad, M., Kniest, E., and Dunlop, R. A. (2019). Boom to bust? Implications for the continued rapid growth of the eastern Australian humpback whale population despite recovery. Popul. Ecol. 61, 198-209. doi: 10.1002/1438-390x. 1014

Nowacek, D. P., Friedlaender, A. S., Halpin, P. N., Hazen, E. L., et al. (2011). Super-aggregations of krill and humpback whales in Wilhelmina Bay, Antarctic Peninsula. PLoS One 6:e19173. doi: 10.1371/journal.pone.0019173

Österblom, H., Bodin, Ö, Sumaila, U. R., and Press, A. J. (2015). Reducing illegal fishing in the Southern Ocean: a global effort. Solutions 4, 72-79.

Pallin, L. J., Baker, C. S., Steel, D., Kellar, N. M., et al. (2018). High pregnancy rates in humpback whales (Megaptera novaeangliae) around the Western Antarctic Peninsula, evidence of a rapidly growing population. R. Soc. Open Sci. 5:180017. doi: 10.1098/rsos.180017

Pardo, D., Forcada, J., Wood, A. G., Tuck, G. N., Ireland, L., Pradel, R., et al. (2017). Additive effects of climate and fisheries drive ongoing declines in multiple albatross species. Proc. Natl. Acad. Sci. U.S.A. 114, E10829-E10837. doi: $10.1073 /$ pnas.1618819114

Payne, M. R. (1979). Fur seals Arctocephalus tropicalis and A. gazella crossing the Antarctic convergence at South Georgia. Mammalia 43, 93-98.

Pertierra, L. R., Hughes, K. A., Vega, G. C., and Olalla-Tárraga, M. Á (2017). High resolution spatial mapping of human footprint across Antarctica and its implications for the strategic conservation of avifauna. PLoS One 12:e0168280. doi: 10.1371/journal.pone.0168280

Pertierra, L. R., Tejedo, P., and Benayas, J. (2014). "Historical developments, drivers of change and future scenarios for human activities on Deception Island," in Antarctic Futures: Human Engagement with the Antarctic Environment, eds T. Tin, D. Liggett, P. T. Maher, and M. Lamers (New York, NY: Springer), 193-211. doi: 10.1007/978-94-007-6582-5_8

Peter, H.-U., Buesser, C., Mustafa, O., and Pfeiffer, S. (2008). Risk Assessment for the Fildes Peninsula and Ardley Island, and Development of Management Plans for Their Designation as Specially Protected or Specially Managed Areas. Research Report 20313 124, UBA-FB 001155e. Available online at: www.umweltbundesamt.de/en/publikationen/riskassessment-for-fildes-peninsula-ardley-island (accessed August 8, 2020).

Phillips, R. A., and Waluda, C. M. (2020). Albatrosses and petrels at South Georgia as sentinels of marine debris input from vessels in the southwest Atlantic Ocean. Environ. Int. 136:105443. doi: 10.1016/j.envint.2019. 105443 
Ralph, R., Maxwell, J. G. H., Everson, I., and Hall, J. (1976). A record of Mytilus edulis L from South Georgia. Br. Antarct. Surv. Bull. 44, 101-102.

Ratnarajah, L., Bowie, A. R., Lannuzel, D., Meiners, K. M., and Nicol, S. (2014). The biogeochemical role of baleen whales and krill in Southern Ocean nutrient cycling. PLoS One 9:e114067. doi: 10.1371/journal.pone.01 14067

Reed, S., Clark, M., Thompson, R., and Hughes, K. A. (2018). Microplastics in marine sediments near Rothera Research Station, Antarctica. Mar. Pollut. Bull. 133, 460-463. doi: 10.1016/j.marpolbul.2018.05.068

Reid, K. (1995). Oiled penguins observed at Bird Island, South Georgia. Mar. Ornithol. 23, 53-57.

Rocha, R. C., Clapham, P. J., and Ivashchenko, Y. V. (2014). Emptying the Oceans: a summary of industrial whaling catches in the $20^{\text {th }}$ Century. Mar. Fish. Rev. 76, 37-48. doi: 10.7755/MFR.76.4.3

Rogers, A. D., Frinault, B. A. V., Barnes, D. K. A., Bindoff, N. L., Downie, R., Ducklow, H. W., et al. (2020). Antarctic futures: an assessment of climatedriven changes in ecosystem structure, function, and service provisioning in the Southern Ocean. Annu. Rev. Mar. Sci. 12, 87-120. doi: 10.1146/annurevmarine-010419-011028

Roman, J., Estes, J. A., Morissette, L., Smith, C., Costa, D., McCarthy, J., et al. (2014). Whales as marine ecosystem engineers. Front. Ecol. Environ. 12:377385. doi: $10.1890 / 130220$

Russell, D. J., Hohberg, K., Otte, V., Christian, A., Potapov, M., Brückner, A., et al. (2013). The Impact of Human Activities on Soil Organisms of the Maritime Antarctic and the Introduction of Non-Native Species in Antarctica. Available online at: http://www.uba.de/uba-info-medien-e/4416.html (accessed August $8,2020)$.

Ryan, P. G. (1987). The origin and fate of artefacts stranded on islands in the African sector of the Southern Ocean. Environ. Conserv. 14, 341-346. doi: $10.1017 / \mathrm{s} 0376892900016854$

Ryan, P. G., de Bruyn, P. N. J., and Bester, M. N. (2016). Regional differences in plastic ingestion among Southern Ocean fur seals and albatrosses. Mar. Pollut. Bull. 104, 207-210. doi: 10.1016/j.marpolbul.2016. 01.032

Ryan, P. G., Dilley, B. J., Ronconi, R. A., and Connan, M. (2019). Rapid increase in Asian bottles in the South Atlantic Ocean indicates major debris inputs from ships. PNAS 116, 20892-20897. doi: 10.1073/pnas.1909816116

Sahade, R., Lagger, C., Torre, L., Momo, F., Monien, P., Schloss, I., et al. (2015). Climate change and glacier retreat drive shifts in an Antarctic benthic ecosystem. Sci. Adv. 1:e1500050. doi: 10.1126/sciadv.1500050

Santora, J. A., and Reiss, C. S. (2011). Geospatial variability of krill and top predators within an Antarctic submarine canyon system. Mar. Biol. 158, 25272540. doi: 10.1007/s00227-011-1753-0

Santora, J. A., Reiss, C. S., Loeb, V. J., and Veit, R. R. (2010). Spatial association between hotspots of baleen whales and demographic patterns of Antarctic krill Euphausia superba suggests size-dependent predation. Mar. Ecol. Prog. Ser. 405, 255-269. doi: 10.3354/meps 08513

Santora, J. A., Schroeder, I. D., and Loeb, V. J. (2014). Spatial assessment of fin whale hotspots and their association with krill within an important Antarctic feeding and fishing ground. Mar. Biol. 161, 2293-2305. doi: 10.1007/s00227014-2506-7

Saunders, R. A., Hill, S. L., Tarling, G. A., and Murphy, E. J. (2019). Myctophid Fish (Family Myctophidae) are central consumers in the food web of the Scotia Sea (Southern Ocean). Front. Mar. Sci. 6:530. doi: 10.3389/fmars.2019.00530

SC-CAMLR (2006). Report of the Twenty-Fifth Meeting of the Scientific Committee for the Conservation of Antarctic Marine Living Resources. Hobart: CCAMLR Secretariat.

Sfriso, A. A., Tomio, Y., Rosso, B., Gambaro, A., Sfriso, A., Corami, F., et al. (2020). Microplastic accumulation in benthic invertebrates in Terra Nova Bay (Ross Sea, Antarctica). Environ. Int. 137:105587. doi: 10.1016/j.envint.2020.105587

Slip, D. J., and Burton, H. R. (1991). Accumulation of fishing debris, plastic litter, and other artefacts, on Heard and Macquarie Islands in the Southern Ocean. Environ. Conserv. 18, 249-254. doi: 10.1017/s0376892900022177

Smale, D. A., Brown, K. M., Barnes, D. K. A., Fraser, K. P. P., and Clarke, A. (2008). Ice scour disturbance in antarctic waters. Science 321:371. doi: 10.1126/science. 1158647
Smith, D. A., and Simpson, R. D. (1995). Effects of the Nella Dan oil spill on the fauna of Durvillaea antarctica holdfasts. Mar. Ecol. Prog. Ser. 121, 73-89. doi: $10.3354 /$ meps 121073

Söffker, M., Trathan, P., Clark, J., Collins, M. A., Belchier, M., and Scott, S. (2015). The impact of predation by marine mammals on Patagonian toothfish longline fisheries. PLoS One 10:e0118113. doi: 10.1371/journal.pone.0118113

Stark, J. S., Conlan, K. E., Hughes, K. A., Kim, S., and Martins, C. C. (2019). Sources, Dispersal and Impacts of Wastewater in Antarctica. Cambridge: Antarctic Environments Portal.

Stark, J. S., Corbett, P. A., Dunshea, G., Johnstone, G., King, C., Mondon, J. A., et al. (2016). The environmental impact of sewage and wastewater outfalls in Antarctica: an example from Davis station, East Antarctica. Water Res. 105, 602-614. doi: 10.1016/j.watres.2016.09.026

Stark, J. S., Mohammad, M., McMinn, A., and Ingels, J. (2017). The effects of hydrocarbons on meiofauna in marine sediments in Antarctica. J. Exp. Mar. Biol. Ecol. 496, 56-73. doi: 10.1016/j.jembe.2017.07.009

Suaria, G., Perold, V., Lee, J. R., Lebouard, F., Aliani, S., and Ryan, P. G. (2020). Floating macro- and microplastics around the Southern Ocean: results from the antarctic circumnavigation expedition. Environ. Int. 136:105494. doi: 10.1016/j. envint.2020.105494

Summerson, R., and Tin, T. (2018). Twenty years of protection of wilderness values in Antarctica. Polar J. 8, 265-288. doi: 10.1080/2154896x.2018.1 541548

Tejedo, P., Benayas, J., Cajiao, D., Albertos, B., Lara, F., Pertierra, L. R., et al. (2016). Assessing environmental conditions of Antarctic footpaths to support management decisions. J. Environ. Manag. 177, 320-330. doi: 10.1016/j. jenvman.2016.04.032

Tejedo, P., Benayas, J., Cajiao, D., Albertos, B., Lara, F., Pertierra, L. R., et al. (2020). Assessing environmental conditions of Antarctic footpaths to support management decisions. J. Environ. Manag. 177, 320-330.

Tejedo, P., Pertierra, L. R., Benayas, J., Convey, P., Justel, A., and Quesada, A. (2012). Trampling on maritime Antarctica: can soil ecosystems be effectively protected through existing codes of conduct? Polar Res. 31:10888. doi: 10.3402/ polar.v31i0.10888

Thatje, S., and Fuentes, V. (2003). First record of anomuran and brachyuran larvae (Crustacea: Decapoda) from Antarctic waters. Polar Biol. 26, 279-282. doi: 10.1007/s00300-002-0476-6

Thompson, R. C., Olsen, Y., Mitchell, R. P., Davis, A., Rowland, S. J., John, A. W. G., et al. (2004). Lost at sea: where is all the plastic? Science 304:838. doi: $10.1126 /$ science. 1094559

Tin, T., Fleming, Z. L., Hughes, Kevin, A., Ainley, D. G., Convey, et al. (2009). Impacts of local human activities on the Antarctic environment. Antarct. Sci. 21, 3-33. doi: 10.1017/S0954102009001722

Tixier, P., Gasco, N., Duhamel, G., and Guinet, C. (2016). Depredation of Patagonian toothfish (Dissostichus eleginoides) by two sympatrically occurring killer whale (Orcinus orca) ecotypes: insights on the behavior of the rarely observed type D killer whales. Mar. Mamm. Sci. 32, 983-1003. doi: 10.1111/ mms. 12307

Torres, D., and Jorquera, D. F. (1995). Línea de base para el seguimiento de los desechos marinos en cabo Shirreff, isla Livingston, Antártica. Baseline for the monitoring of marine debris at Cape Shirreff, Livingston Island, Antarctica. Serie Cientifica. Inst. Antart. Chileno 45, 131-141.

Trebilco, R., Melbourne-Thomas, J., and Constable, A. J. (2020). The policy relevance of Southern Ocean food web structure: implications of food web change for fisheries, conservation and carbon sequestration. Mar. Policy 115, 1-7. doi: 10.1016/j.marpol.2020.103832

Turner, J., and Comiso, J. (2017). Solve Antarctica's sea-ice puzzle. Nature 547, 275-277. doi: $10.1038 / 547275$ a

United Kingdom, Argentina, Chile in conjunction with the International Association of Antarctica Tour Operators (2018). "Data collection and reporting on yachting activity in antarctica in 2018-19," Information Paper 107 Rev 1, Presented to the Antarctic Treaty Consultative Meeting XLII, Prague.

Van Franeker, J. A., and Bell, P. J. (1988). Plastic ingestion by petrels breeding in Antarctica. Mar. Pollut. Bull. 19, 672-674. doi: 10.1016/0025-326x(88)90388-8

Walker, T. R., Reid, K., Arnould, J. P. Y., and Croxall, J. P. (1997). Marine debris surveys at Bird Island, South Georgia 1990-1995. Mar. Pollut. Bull. 34, 61-65. doi: 10.1016/s0025-326x(96)00053-7 
Waller, C. L., Griffiths, H. J., Waluda, C. M., Thorpe, S. E., Loaiza, I., Moreno, B., et al. (2017). Microplastics in the Antarctic marine system: an emerging area of research. Sci. Total Environ. 598, 220-227. doi: 10.1016/j.scitotenv.2017. 03.283

Waluda, C. M., and Staniland, I. J. (2013). Entanglement of Antarctic fur seals at Bird Island, South Georgia. Mar. Pollut. Bull. 74, 261-274.

Waluda, C. M., Staniland, I. J., Dunn, M. J., Thorpe, S. E., Grilly, E., Whitelaw, M., et al. (2020). Thirty years of marine debris in the Southern Ocean: annual surveys of two island shores in the Scotia Sea. Environ. Int. 136:105460. doi: 10.1016/j.envint.2020.105460

Ward, E., Zerbini, A. N., Kinas, P. G., Engel, M. H., and Andriolo, A. (2011). Estimates of population growth rates of humpback whales (Megaptera novaeangliae) in the wintering grounds off the coast of Brazil (Breeding Stock A). J. Cetacean Res. Manag. 3, 145-149. doi: 10.47536/jcrm.vi3.323

Watters, G. M., Hill, S. L., Hinke, J. T., Matthews, J., and Reid, K. (2013). Decisionmaking for ecosystem-based management: evaluating options for a krill fishery with an ecosystem dynamics model. Ecol. Appl. 23, 710-725. doi: 10.1890/121371.1

Watters, G. M., Hinke, J. T., and Reiss, C. S. (2020). Long-term observations from Antarctica demonstrate that mismatched scales of fisheries management and predator-prey interaction lead to erroneous conclusions about precaution. Sci. Rep. 10:2314.

Weinstein, B., Double, M., Gales, N., Johnston, D., and Friedlaender, A. S. (2017). Identifying overlap between humpback whale foraging grounds and the Antarctic krill fishery. Biol. Conserv. 210, 184-191.

Welsford, D., Ewing, G., Constable, A., Hibberd, T., and Kilpatrick, R. (2014). Demersal Fishing Interactions With Marine Benthos in the Australian EEZ of the Southern Ocean: An Assessment of the Vulnerability of Benthic Habitats to
Impact by Demersal Gears. Kingston TAS: Australian Antarctic Division, and Fisheries Research and Development Corporation.

Wild, S., McLagan, D., Schlabach, M., Bossil, R., Hawker, D., Cropp, R., et al. (2015). An antarctic research station as a source of brominated and perfluorinated persistent organic pollutants to the local Environment. Environ. Sci. Technol. 49, 103-112. doi: 10.1021/es5048232

Wilkness, P. (1990). Fuel spill clean up in the Antarctic. Antarct. J. United States 25, $3-8$.

Zerbini, A. N., Adams, G., Best, J., Clapham, P. J., Jackson, J. A., and Punt, A. E. (2019). Assessing the recovery of an Antarctic krill predator from historical exploitation. Sci. Rep. 6:190368. doi: 10.1098/rsos.19 0368

Zwerschke, N., Morley, S. A., Peck, L. S., and Barnes, D. K. A. (2021). Can Antarctica's shallow zoobenthos 'bounce back' from iceberg scouring impacts driven by climate change? Glob. Change Biol. 27, 3157-3165. doi: 10.1111/gcb. 15617

Conflict of Interest: The authors declare that the research was conducted in the absence of any commercial or financial relationships that could be construed as a potential conflict of interest.

Copyright (c) 2021 Grant, Waller, Morley, Barnes, Brasier, Double, Griffiths, Hughes, Jackson, Waluda and Constable. This is an open-access article distributed under the terms of the Creative Commons Attribution License (CC BY). The use, distribution or reproduction in other forums is permitted, provided the original author(s) and the copyright owner(s) are credited and that the original publication in this journal is cited, in accordance with accepted academic practice. No use, distribution or reproduction is permitted which does not comply with these terms. 